\title{
Evaluation of a constitutive model for clays and sands: Part II - clay behaviour
}

\author{
Juan M. Pestana ${ }^{1, *, \dagger}$, Andrew J. Whittle ${ }^{2}$ and Antonio Gens ${ }^{3}$ \\ ${ }^{1}$ University of California, Berkeley, CA, U.S.A \\ ${ }^{2}$ Massachusetts Institute of Technology, Cambridge, MA, U.S.A \\ ${ }^{3}$ Technical University of Catalonia, Barcelona, Spain
}

\begin{abstract}
SUMMARY
The undrained response of cohesive soils is of paramount importance in geomechanics and it has been modelled extensively for the last 50 years. In comparison, drained behaviour of clays has received only modest attention. Drained and undrained behaviour is significantly affected by past consolidation stress history. This paper evaluates the capabilities of the MIT-S1 effective stress model, described in a companion paper, for predicting the anisotropic stress-strain-strength behaviour of clays. The paper illustrates the selection of model parameters for Lower Cromer Till, using data from standard types of laboratory tests. Comparison of model simulations with measured response for Lower Cromer Till and Boston Blue Clay illustrate model capabilities. The work focuses initially on comparisons of model predictions with measurements from undrained triaxial and plane strain tests on initially $K_{0}$-consolidated specimens. Comparisons with measured data from undrained shear tests performed in different modes of shearing for LCT and BBC show that the model: (a) gives excellent predictions of maximum shear stress conditions and accurately describes the non-linear shear stress-strain behaviour; (b) accurately describes the anisotropic shear stress-strain-strength conditions for different consolidation stress histories; and (c) gives realistic description of mobilized friction angles, especially at large OCR's. The paper then focuses on the effects of consolidation stress history for isotropically consolidated specimens of resedimented Lower Cromer Till and Boston Blue Clay. Finally, the paper compares model predictions for drained shear tests on $K_{0}$ and isotropically consolidated specimens with overconsolidation ratios, OCR $\leqslant 10$, used to evaluate particular aspects of the critical state framework of soil behaviour. Overall, the model gives excellent predictions of the effect of initial anisotropy and overconsolidation stress history on the shear stress-strain and volumetric behaviour of clays. Copyright (C) 2002 John Wiley \& Sons, Ltd.
\end{abstract}

KEY WORDS: undrained shear strength; clay behaviour; anisotropy; stress history

\footnotetext{
*Correspondence to: Juan M. Pestana, Geoengineering Group, Department of Civil and Environmental Engineering, 440 Davis Hall-1710, Berkeley, CA 94720-1710, U.S.A.

${ }^{\dagger}$ E-mail: pestana@ce.berkeley.edu
}

Contract/grant sponsor: National Science Foundation; contract/grant number: CMS 9623979

Copyright (C) 2002 John Wiley \& Sons, Ltd.

Received 22 August 2001 Revised 11 February 2002 


\section{INTRODUCTION}

A new effective stress soil model, hereafter referred to as MIT-S1, was developed to model the rate independent behaviour of clays, sands and silts in a single conceptual framework [1]. A brief summary of the model formulation is presented in a companion paper and full details of the constitutive laws are available in the literature [2]. Detailed comparisons with high-quality laboratory test data are essential in order to establish the predictive capabilities and limitations of the proposed model at the element level, prior to its application in numerical analyses of boundary value problems. A companion paper demonstrates the predictive capabilities of MIT$\mathrm{S} 1$ for describing the behaviour of sands over a wide range of stress levels and densities. This paper focuses on illustrating model capabilities to describe the rate independent behaviour of clays through comparisons with high-quality laboratory test data for Lower Cromer Till, LCT and Boston Blue Clay, BBC. Lower Cromer Till is classified as a low plasticity sandy silty-clay (CL; with liquid limit, $w_{1}=25 \%$, and plasticity index, $I_{\mathrm{p}}=13 \%$ ), and a $17 \%$ clay fraction (mainly calcite and illite). The tests on LCT were all performed on specimens consolidated from a slurry condition with an initial liquidity index, $I_{1}=1.5(w=31 \%)$. The database includes both drained and undrained triaxial shear tests on $K_{0}$-consolidated specimens with overconsolidation ratios, $\mathrm{OCR} \leqslant 10$, as well as numerous special stress path (drained) tests used to evaluate particular aspects of the critical state framework of soil behaviour [3]. The data for LCT were not available in digital or table format and it was retrieved by directly digitizing hardcopy

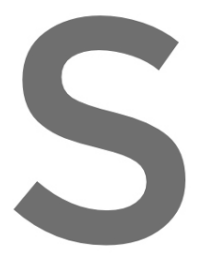
graphs of all tests. Bost
$w_{1} \approx 42 \%$ and plasticit
illite) of moderate sens
glaciation. Engineering
extensively at MIT and model input parameters [4]
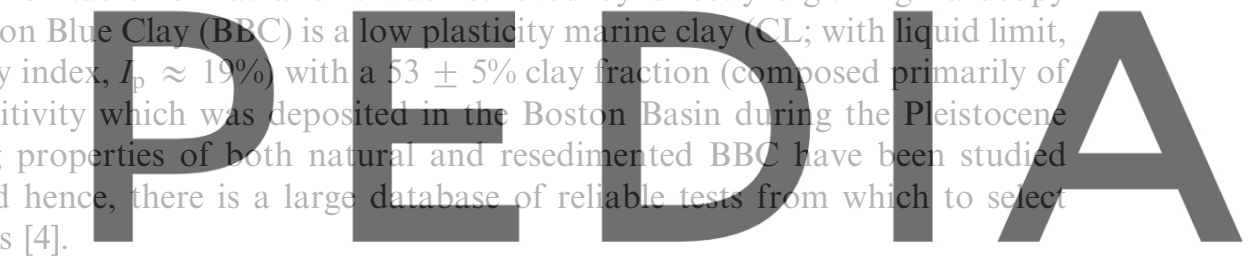

Register for free at https//www.scipedia.com to download the version without the watermark

\section{DETERMINATION OF MATERIAL CONSTANTS}

In its most general form, the MIT-S1 model requires 16 material parameters but only 13 of those are required to model the behaviour of clays. This section illustrates the procedure used to determine all the model material parameters for Lower Cromer Till, LCT (cf. Table I). All the material parameters for the model are obtained from standard laboratory data, which include:

1. One-dimensional or isotropic (e.g. triaxial) consolidation tests to stresses significantly larger than the preconsolidation pressure with accurate volumetric measurements during unload-reload cycles.

2. Lateral stress measurements during one-dimensional compression and swelling using high quality computer controlled triaxial test equipment [5] or using a lateral stress oedometer [6].

3. Undrained triaxial compression $\left(\mathrm{CK}_{0} \mathrm{UC}\right)$ and extension $\left(\mathrm{CK}_{0} \mathrm{UE}\right)$ shear tests on normally $K_{0}$-consolidated (resedimented) clay. These tests should use SHANSEP consolidation procedures, which ameliorate the effects of sample disturbance [7] and are consistent with assumptions of normalized soil behaviour assumed in the MIT-S1 model formulation. 
Table I. Input material parameters for the MIT-S1 model.

\begin{tabular}{|c|c|c|c|c|}
\hline Test type & Parameter/symbol & Physical contribution/meaning & $\begin{array}{l}\text { Lower } \\
\text { Cromer } \\
\text { Till }\end{array}$ & $\begin{array}{l}\text { Boston } \\
\text { Blue Clay }\end{array}$ \\
\hline $\begin{array}{l}\text { Hydrostatic or } \\
\text { 1-D Compression } \\
\text { (triaxial, } \\
\text { oedometer or } \\
\text { CRS apparatus) }\end{array}$ & $\begin{array}{l}\rho_{\mathrm{c}} \\
D \\
r \\
h\end{array}$ & $\begin{array}{l}\text { Compressibility of normally } \\
\text { consolidated (NC) clay } \\
\text { Non-linear volumetric } \\
\text { Swelling behaviour } \\
\text { Irrecoverable plastic strain }\end{array}$ & $\begin{array}{c}0.167 \\
0.04 \\
0.80 \\
6.0\end{array}$ & $\begin{array}{c}0.178 \\
0.04 \\
0.85 \\
6.0\end{array}$ \\
\hline $\begin{array}{l}K_{0} \text {-oedometer } \\
\text { or } \\
K_{0} \text {-triaxial }\end{array}$ & $\begin{array}{c}K_{0 \mathrm{NC}} \\
\mu_{0}^{\prime} \\
\omega\end{array}$ & $\begin{array}{l}K_{0} \text { for NC clay } \\
\text { Poisson's ratio at stress reversal } \\
\text { controlling } 2 G_{\max } / K_{\max } \\
\text { Non-linear Poisson's ratio. Stress path } \\
\text { in } 1 \text {-D unloading }\end{array}$ & $\begin{array}{l}0.50 \\
0.225 \\
0.60\end{array}$ & $\begin{array}{l}0.49 \\
0.24 \\
1.0\end{array}$ \\
\hline $\begin{array}{l}\text { Undrained triaxial } \\
\text { shear tests: } \\
\text { OCR }=1 ; \mathrm{CK}_{0} \mathrm{UC} \\
\mathrm{OCR}=1 ; \mathrm{CK}_{0} \mathrm{UE} \\
\left(\mathrm{CK}_{0} \mathrm{UC} ; \mathrm{OCR}>1 ;\right. \\
\text { Optional) } \\
\text { Shear wave velocity/ } \\
\text { resonant column }\end{array}$ & $\begin{array}{l}\phi_{\mathrm{cs}}^{\prime} \\
\phi_{m}^{\prime} \\
m \\
\omega_{\mathrm{s}} \\
\psi\end{array}$ & $\begin{array}{l}\text { Critical state friction angle in triaxial } \\
\text { compression } \\
\text { Geometry of bounding surface. Stress } \\
\text { paths of undrained CK } \mathrm{CK}_{0} \mathrm{UTC} / \mathrm{TE} \text { tests } \\
\text { Small strain non-linearity in shear } \\
\text { Rate of evolution of anisotropy } \\
\text { (rotation of bounding surface) }\end{array}$ & $\begin{array}{c}30.0^{\circ} \\
42.0^{\circ} \\
0.65 \\
8.0 \\
20\end{array}$ & $\begin{array}{c}33.5^{\circ} \\
46.0^{\circ} \\
0.80 \\
8.0 \\
15\end{array}$ \\
\hline
\end{tabular}

Figure 1 shows that the behaviour of resedimented Lower Cromer Till (in both hydrostatic and $K_{0}$ compression) is well described by a linear normal compression line (NCL) in a double logarithmic void ratio-effective stress space with compression coefficient $\rho_{\mathrm{c}}=0.167(0.16-0.17)$. Pestana [1] proposes that, for mathematical purposes, the normal compression line can be represented by the limiting compression curve, LCC, and therefore the same framework can be used to describe the behaviour of clays and sands [8]. For the typical stress and density conditions encountered in geotechnical practice, the location of the LCC for clays is a function of the current void ratio and preconsolidation pressure (i.e. consolidation stress-history) and the LCC slope, $\rho_{\mathrm{c}}$.

Parameter $C_{\mathrm{b}}$ controls the elastic shear and bulk modulus at small strain levels. For the MIT$\mathrm{S} 1$ model an average value of $C_{\mathrm{b}}=450(350-500)$ is chosen for LCT which is estimated from measured small strain measurements $\left(\varepsilon_{\mathrm{a}} \leqslant 0.005 \%\right)$ in standard triaxial tests of $K_{0}$-resedimented LCT [9]. This parameter could be better estimated from shear wave velocity measurements using bender elements, which are becoming more common in current laboratory testing. Parameters $D$ and $r$ describe the hysteretic volumetric response. Parameter $D$ is selected as the slope of the unloading curve at OCR $\geqslant 10$, while parameter $r$ is selected from a short parametric study to match the stress-strain behaviour in an oedometer (or CRS test) at intermediate values of OCR. 

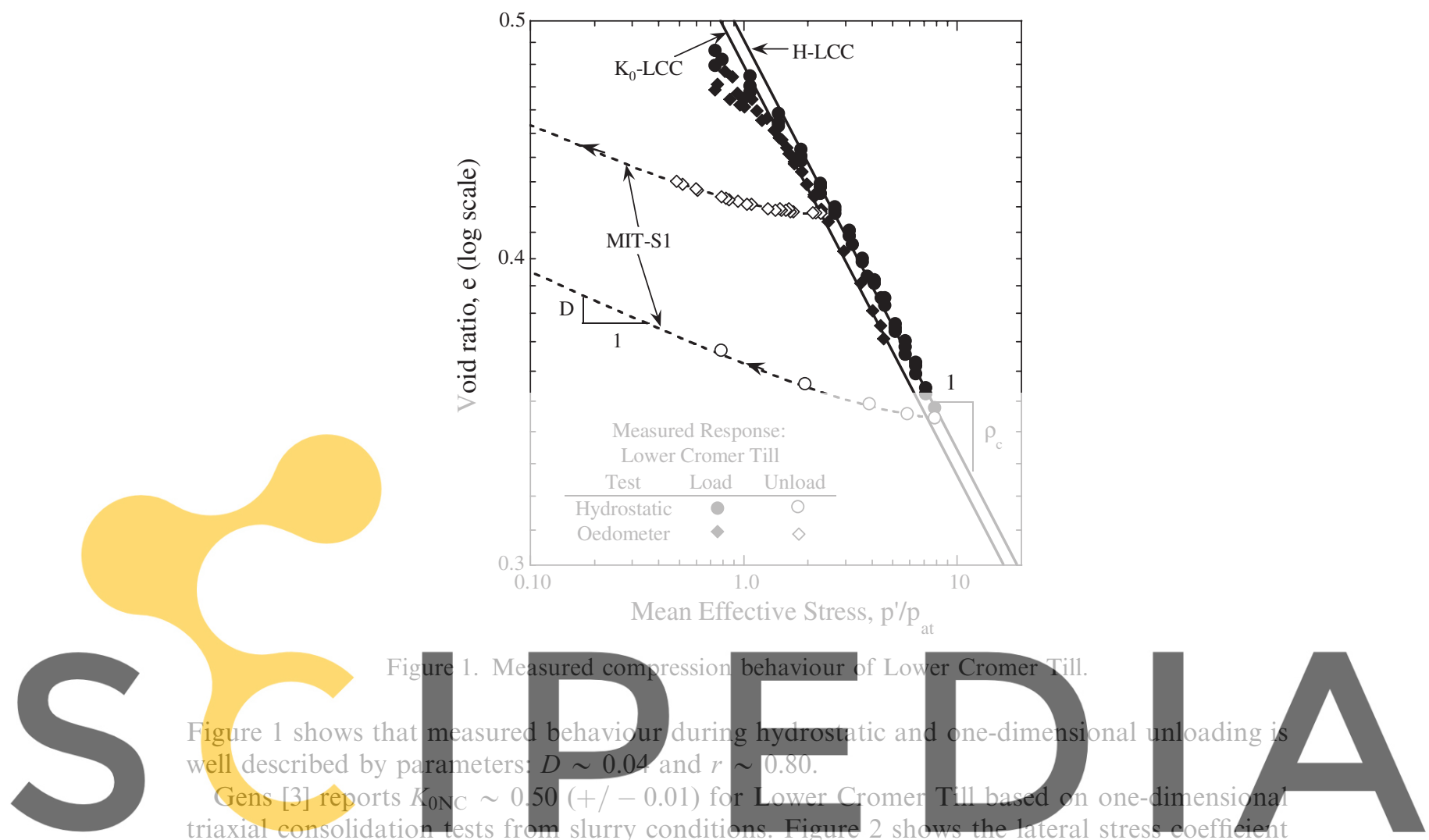

during 1-D unloading for LCT as a function of overconsolidation ratio from which is possible to

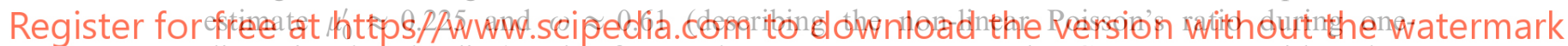
dimensional unloading). The figure also compares measured LCT response with values predicted using a constant Poisson's ratio assumption and with a widely used empirical correlation. The expression, $K_{0}=K_{0 \mathrm{NC}} \mathrm{OCR}^{\mathrm{m}}$, gives excellent predictions for $\mathrm{OCR}<2$ with an exponent $m \sim 0.4$ (typically reported in the literature [10]), but significantly underestimates $K_{0}$ at larger OCRs. The constant Poisson's ratio assumption gives excellent prediction up to OCR $\sim 4$, but overpredicts the response at larger OCRs. The nonlinear Poisson's ratio formulation used in MIT-S1 gives excellent prediction of $K_{0}$, and hence the swelling path, for $\mathrm{OCR}<10$.

The parameter $\omega_{\mathrm{s}}$ describes small strain non-linearity in shear and it is evaluated through the analysis of shear modulus degradation with strain level. Accurate measurements of soil stiffness in the range $0.005 \leqslant \varepsilon_{\mathrm{a}} \leqslant 0.05 \%$ can be achieved using local strain measurements [11,12]. Figure 3 shows the stress-strain curves for triaxial compression and extension tests starting from a normally consolidated condition $\left(K_{0} \sim 0.5\right)$ in a modified strain space (i.e. log-strains) to highlight the importance of small strain non-linearity. Parameter determination is more reliable when there are large changes in stress ratio (e.g. triaxial extension tests are more useful when $K_{0}<1$, while compression tests are preferred for $\left.K_{0}>1\right)$ and requires the accurate measurement of the stress-strain curves at small strains. Note that the behaviour in compression from a normally consolidated $K_{0}$ state is significantly influenced by the shape of the yield/bounding surface at strains as low as $0.1-0.2 \%$. On the other hand, the effective stress path of a $\mathrm{CK}_{0}$ 


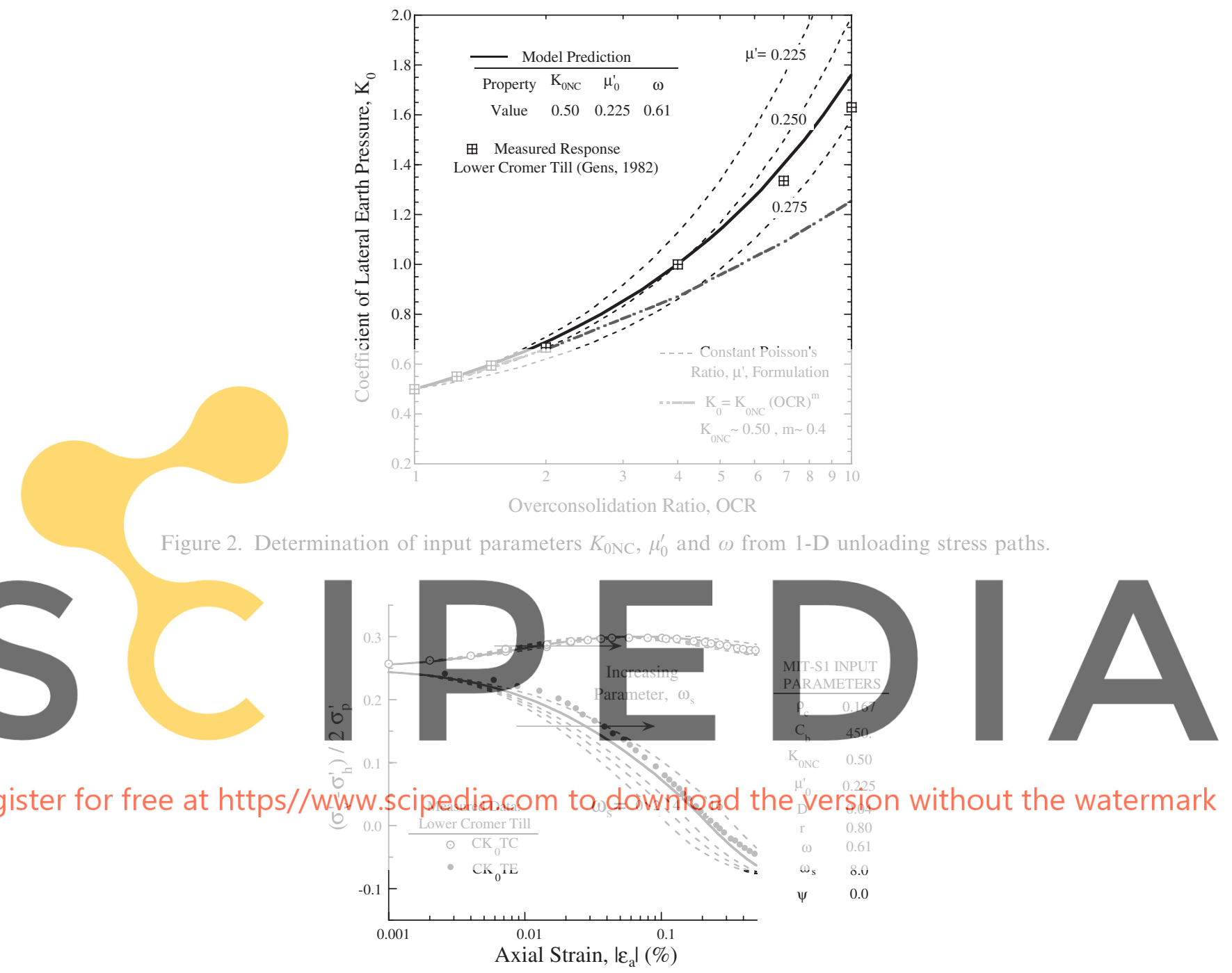

Figure 3. Determination of small strain non-linearity in shear, $\omega_{\mathrm{s}}$.

undrained extension test closely resembles a constant mean effective stress with little influence of the shape of the bounding surface. Alternatively, an undrained triaxial compression test on an overconsolidated specimen may yield similar results if the initial stiffness is matched using shear wave velocity measurements. Since $\omega_{\mathrm{s}}$ describes the reduction in the shear stiffness as a function of strain after reversal, it is of paramount importance to accurately determine the small strain stiffness, $G_{\max }$. The uncertainty (or error) in the value of $G_{\max }$ will introduce a consistent bias in the value of $\omega_{\mathrm{s}}$. For $K_{0}$-consolidated clays, this parameter can be determined by matching the predicted stress-strain curves for triaxial extension tests at small strains $\left(\varepsilon_{\mathrm{a}}<0.1-0.2 \%\right)$ since the effect of plastic strains, in general, is negligible at these small strain levels. For $K_{0}$-consolidated LCT, parameter $\omega_{\mathrm{s}} \sim 8$ gives a good representation of small strain nonlinearity. 
The friction angle at critical state (large strain) conditions, $\phi_{\mathrm{cs}}^{\prime}=30^{\circ}$, is reliably estimated at $\varepsilon_{\mathrm{a}} \geqslant 10 \%$ from undrained triaxial compression tests. Figure 4 shows the effects of selected pairs of parameters $\phi_{m}^{\prime}$ and $m$ matching undrained strength in triaxial compression on model simulations of undrained triaxial compression and extension tests (i.e. $\mathrm{CK}_{0} \mathrm{UC}$ and $\mathrm{CK}_{0} \mathrm{UE}$ ), assuming no change in initial anisotropy, (i.e. $\psi=0$ ). For mathematical simplicity, it is assumed that the aperture of the bounding surface for clays does not change with changes in density and hence $\phi_{m}^{\prime}=\phi_{m r}^{\prime}=$ constant (where $\phi_{m r}^{\prime}$ is the aperture at a reference void ratio of one). The three potential scenarios shown in Figure 4 give essentially the same undrained shear strength in compression, however, as parameter $m$ increases (and therefore $\phi_{m}^{\prime}$ decreases), there is an increase in excess pore pressure in extension (reduction of mean effective stress). For the remainder of the paper, the effective stress paths will be plotted in the Mohr space $\left(\sigma_{\mathrm{v}}-\sigma_{\mathrm{h}}\right) / 2 \mathrm{vs}$ $\left(\sigma_{\mathrm{v}}+\sigma_{\mathrm{h}}\right) / 2$, instead of the more common $p-q$ space. Maximum absolute values of $\left(\sigma_{\mathrm{v}}-\sigma_{\mathrm{h}}\right) / 2$ will indicate directly the values of undrained shear strength, $s_{u}$. Positive values of $\left(\sigma_{v}-\sigma_{h}\right) / 2$ will represent compression while negative values will represent extension. Selected values of $\phi_{m}^{\prime}=42^{\circ}$ and $m=0.65$ give good predictions of the initial effective stress paths in compression
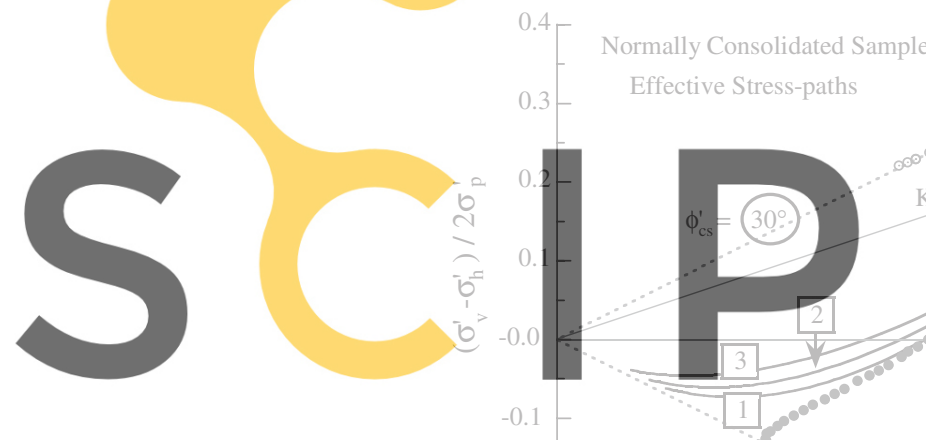

Normally Consolidated Samples
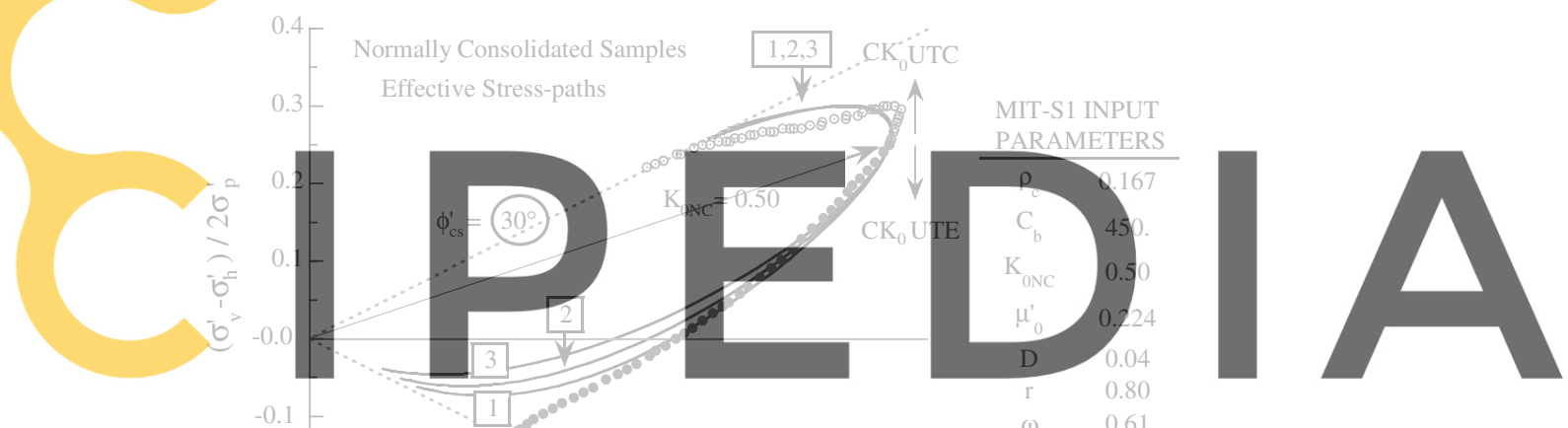

Register for free at https//www.scipedia,com to download the versionswithout the watermark
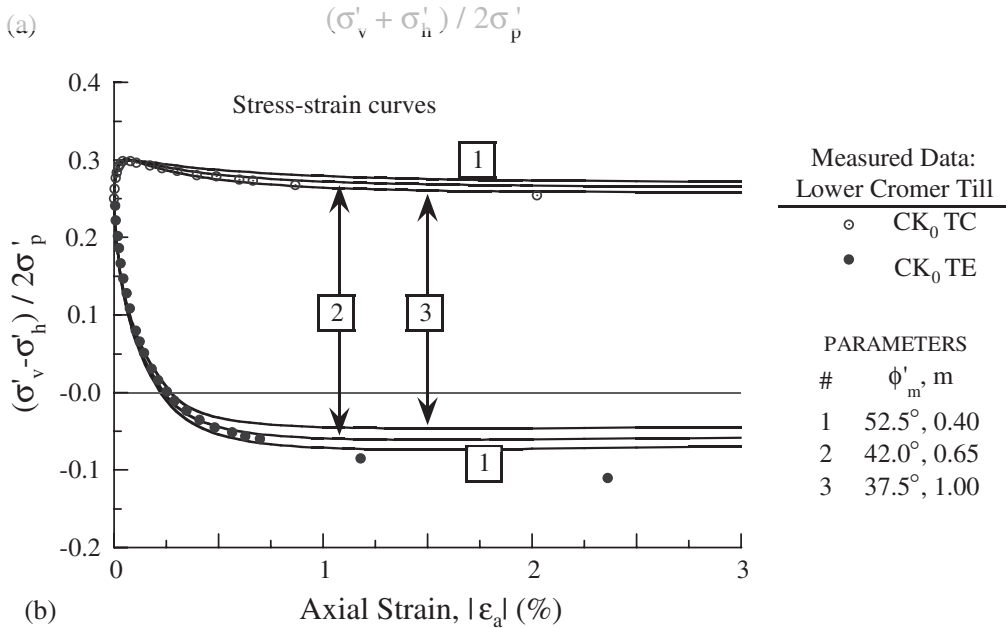

(b)

Axial Strain, $\left|\varepsilon_{\mathrm{a}}\right|(\%)$

Figure 4. Estimation of bounding surface parameters from the undrained response of Lower Cromer Till. 
and extension and are used for the remaining of the paper. The selection of parameter $\omega_{\mathrm{s}}=8$ does not significantly affect the shape of the bounding surface and hence the selection of parameters $\phi_{m}^{\prime}$ and $m$.

The rotational hardening parameter $\psi$ can be estimated from the simulation of the shear induced pore pressures or stress-strain curves at relative large strains $\left(\varepsilon_{\mathrm{a}}=5-10 \%\right)$ from the same undrained triaxial shear tests $\left(\mathrm{CK}_{0} \mathrm{UC}, \mathrm{CK}_{0} \mathrm{UE}\right)$ described earlier. Figure 5 compares model predictions for $\psi=0,10,20$ and 40 with measured data on $K_{0}$-normally consolidated LCT. The results show two key features of the model: (a) changes in $\psi$ do not affect the effective stress paths in the compression mode, but are an important factor controlling shear induced
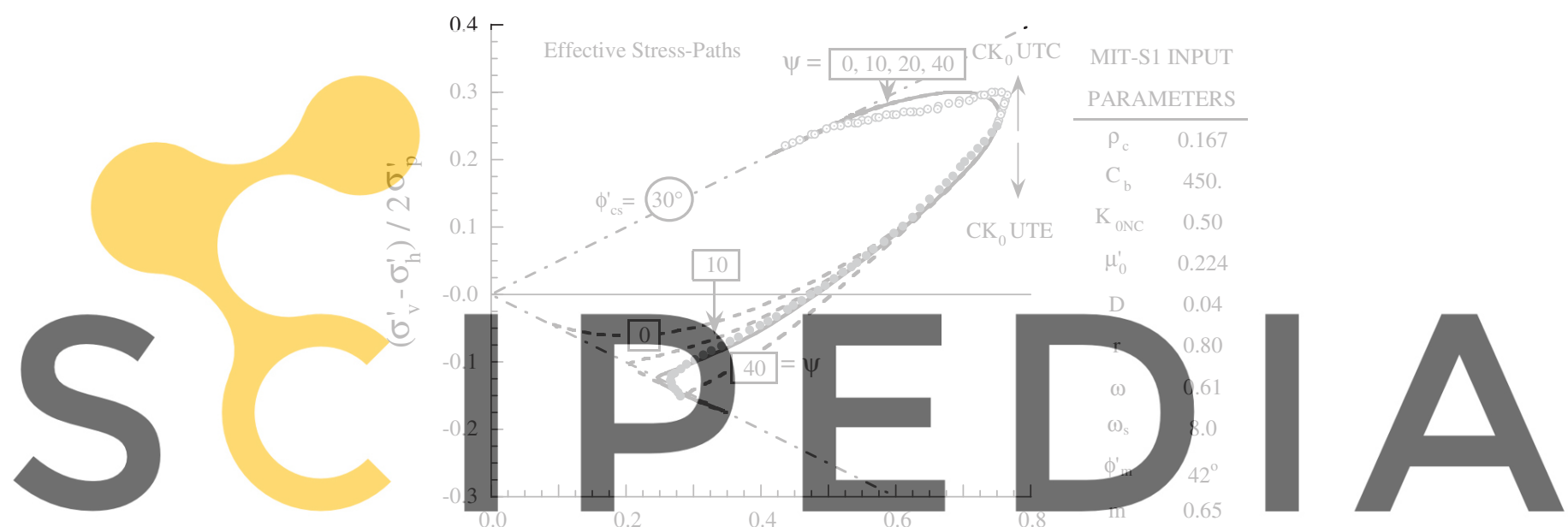

Register for free at https//www.scipedia.com to download the version without the watermark

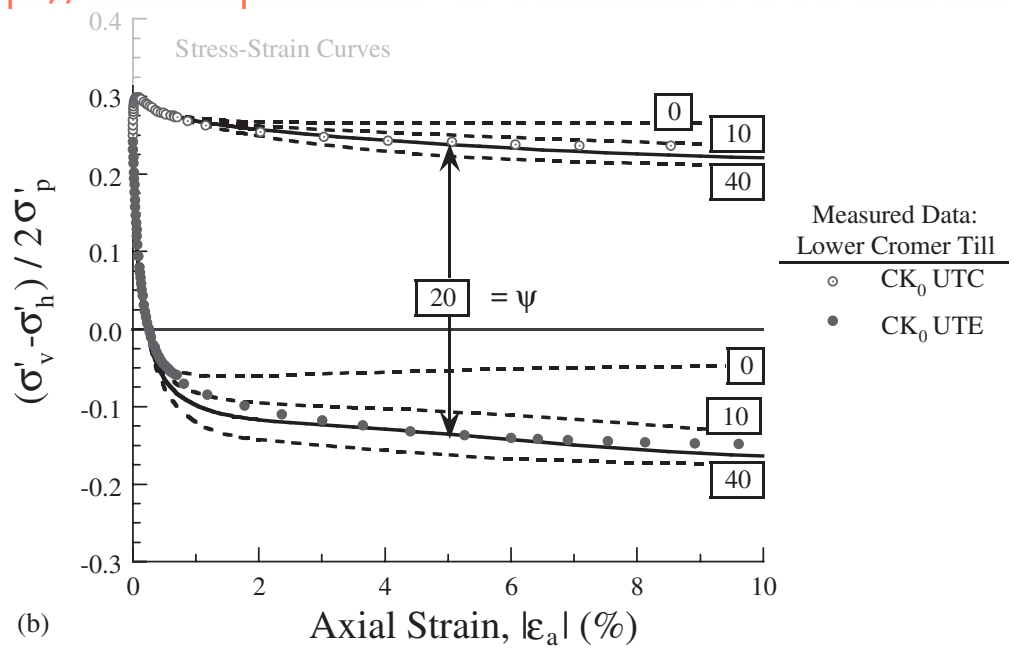

Figure 5. Estimation of parameter $\psi$ from undrained response of normally consolidated Lower Cromer Till. 

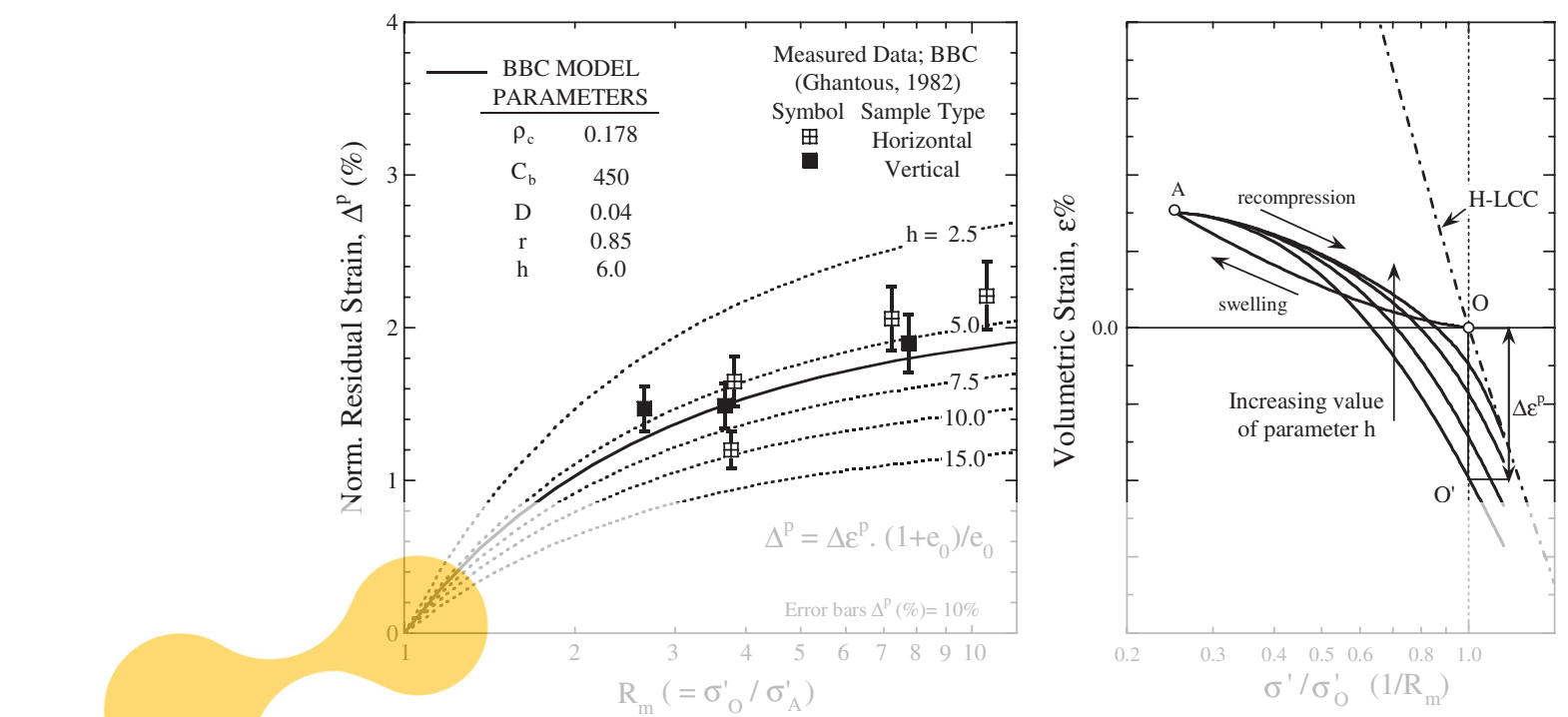

Figure 6. Determination of parameter $h$ from the unload-reload cycles in constant rate of strain consolidation tests for Boston Blue Clay.
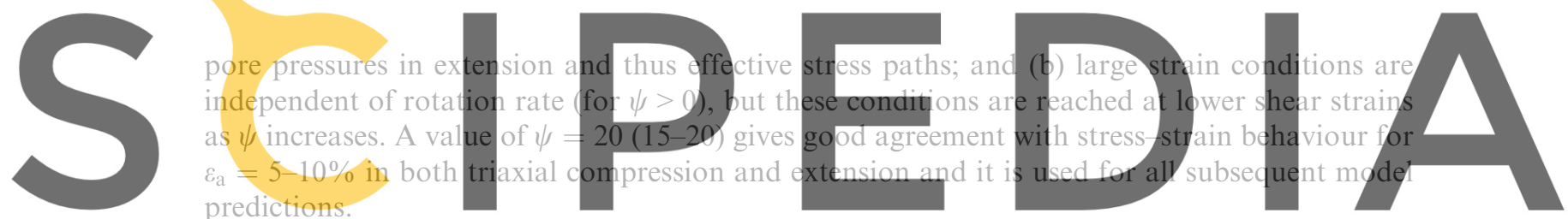

The parameter $h$ controls the amount of normalized residual plastic strain observed in

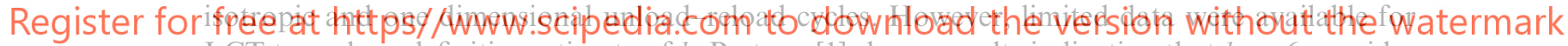
LCT to make a definitive estimate of $h$. Pestana [1] shows results indicating that $h \sim 6$ provides good description of overconsolidated response and it is used throughout the analysis. A similar value was obtained for Boston Blue Clay based on unload-reload cycles in one-dimensional compression and is shown in Figure 6. Two important observations follow: (a) the residual deformation increases as the magnitude of the unload-reload cycle increases, (b) for a given cycle of stresses, the residual deformation decreases as input parameter $h$ increases. A summary of all input parameters for Lower Cromer Till and Boston Blue Clay is presented in Table I.

\section{UNDRAINED SHEAR BEHAVIOUR}

\subsection{Undrained triaxial shearing}

Figures 7(a) and 7(b) show the effective stress paths and shear stress-strain response measured in undrained triaxial compression and extension tests $\left(\mathrm{CK}_{0} \mathrm{UC}, \mathrm{CK}_{0} \mathrm{UE}\right)$ for specimens with overconsolidation ratios, $\mathrm{OCR}=\sigma_{\mathrm{p}}^{\prime} / \sigma_{\mathrm{vc}}^{\prime}=1,1.5,2,4,7$ and 10 . Some of the tests were performed at a relatively slow shear rate, $\Delta \dot{\varepsilon}_{\mathrm{a}}=0.04 \% / \mathrm{h}$, in contrast to the standard strain rate of $\Delta \dot{\varepsilon}_{\mathrm{a}} \leqslant 0.5 \% / \mathrm{h}$. The strain rate has a relatively minor effect on the behaviour of 


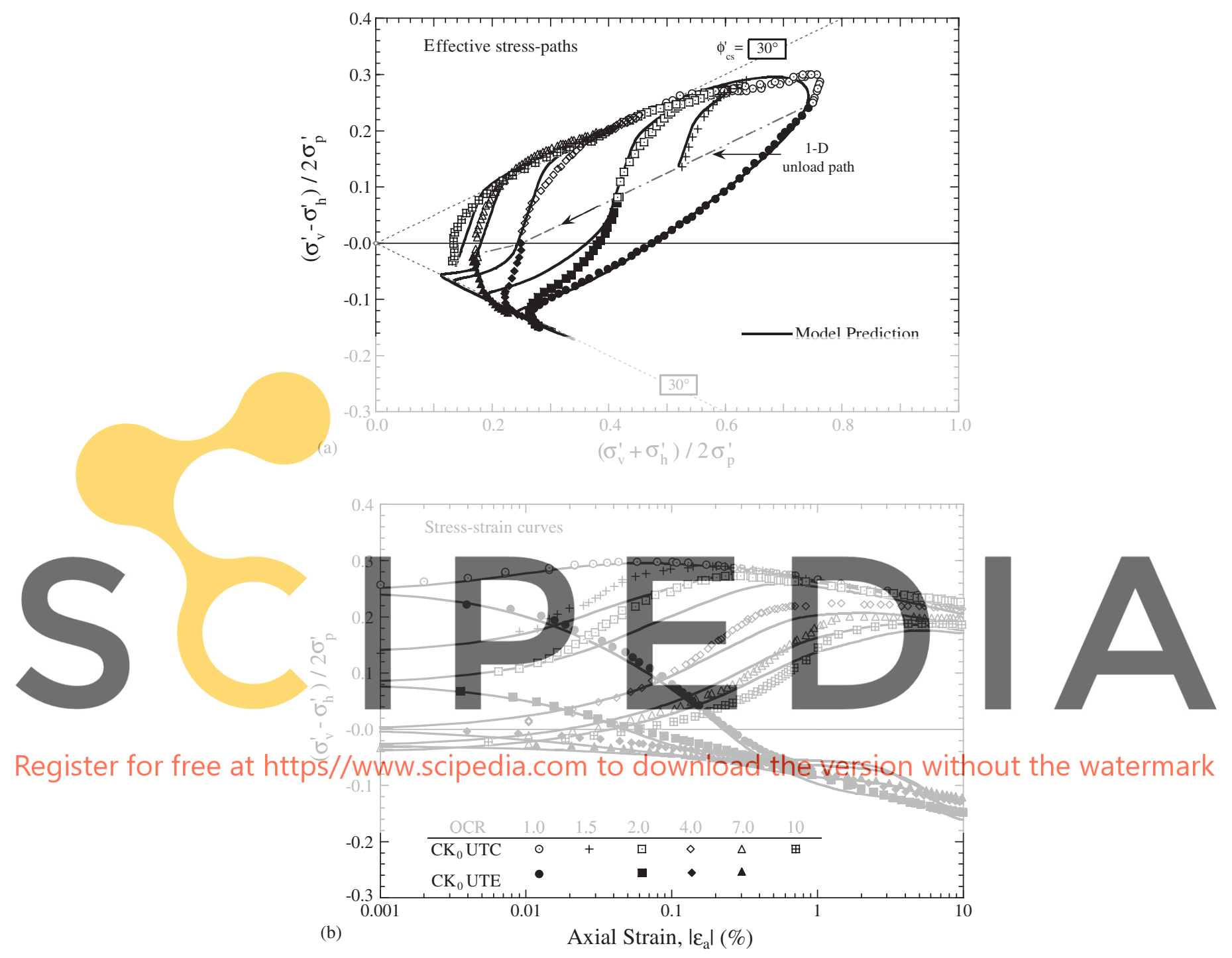

Figure 7. Effect of overconsolidation stress history on the undrained response of Lower Cromer Till.

overconsolidated specimens, but it does affect the pre-peak shear induced pore water pressures and undrained shear strength in tests at $\mathrm{OCR}<1.5$. Good agreement is expected for OCR $=1$ since this set was used for the selection of material parameters, while results for OCR $\neq 1$ can be properly classified as model predictions. The laboratory samples were reconsolidated following SHANSEP procedures and then rebounded to the required OCR, while model predictions are obtained by simulating swelling from a virgin normally consolidated condition (i.e. one in which the principal directions of stress and anisotropy coincide for $K_{0}$-normal consolidation). 
Comparison of MIT-S1 predictions with measured data for LCT shows the following:

1. The model predictions are generally in good agreement with the measured stress-strain behaviour for both triaxial compression and extension, but the model tends to underestimate the stiffness in the range $0.05 \leqslant \varepsilon_{\mathrm{a}} \leqslant 0.5 \%$ for OCR $\geqslant 4$ in compression and for all overconsolidated samples in extension (cf. Figure 7(b)). For slightly overconsolidated samples (e.g. OCR $\leqslant 4$ ), predicted undrained strengths are in excellent agreement with measured data, while the model slightly underpredicts measured strength by $5-10 \%$ at $\mathrm{OCRs}=7$ and 10 .

2. The model gives excellent predictions of shear induced pore pressures and stress obliquities for $\mathrm{CK}_{0} \mathrm{UC}$ tests at all OCRs as evidenced by the agreement between predicted and measured stress paths (cf. Figure 7(a)). The predicted effective stress paths in extension $\left(\mathrm{CK}_{0} \mathrm{UE}\right)$ initially show positive shear induced pore pressure (tendency to contract) and only dilate as the obliquity approaches critical state conditions. In contrast, the measured data develops negative shear induced pore pressures throughout the entire test, leading to a large apparent discrepancy in the effective stress paths.

Figure $8(a)$ compares predictions of effective stress paths for undrained triaxial compression and extension tests with measured data for resedimented $\mathrm{BBC}$ with initial $\mathrm{OCR}=1,2,4$ and 8. Figure 8 (b) compares model predictions with measured shear stress-strain behaviour of undrained triaxial tests for $K_{0}$-consolidated samples. A number of key features can be observed
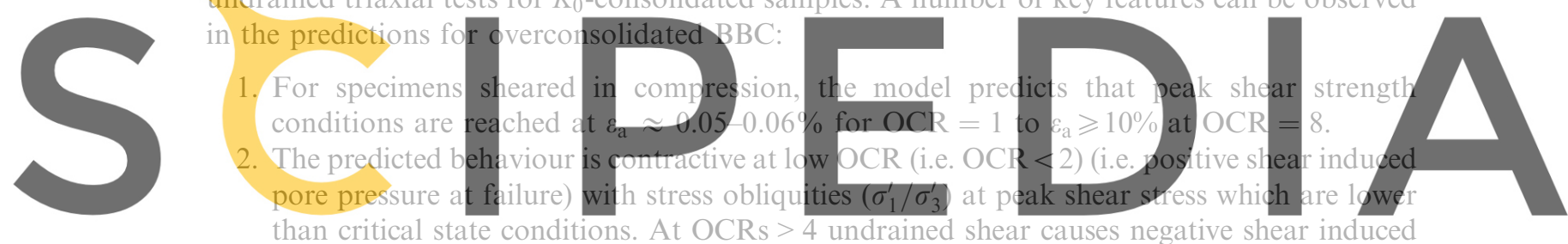

than critical state conditions. At OCRs $>4$ undrained shear causes negative shear ind

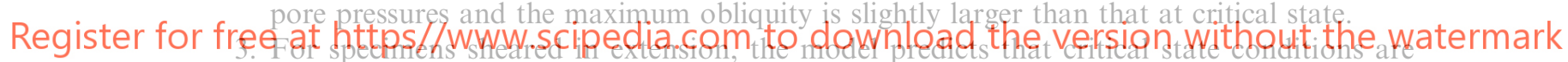

reached at large strains $\varepsilon_{\mathrm{a}} \geqslant 20 \%$ with stress obliquities that are slightly higher than critical

state conditions for all values of OCR.

The model predicts that the stress-strain behaviour is non-linear over the full range of measured strains (no 'distinct' yielding is observed) for both normally and overconsolidated samples. The model gives excellent predictions of the shear stressstrain-strength behaviour for OCR $=2,4$ and 8 for the database by Sheahan (1991). Peak stress obliquities in compression are well described by the MIT-S1 model, especially at high OCR and hence, improve one of the noted limitations of the MIT-E3 model [13]. In triaxial extension, model predictions are generally in very good agreement with measured stressstrain data for strains less than $1-2 \%$ and are in excellent agreement with mobilized friction angles observed by Sheahan [4], but the model tends to overpredict the undrained shear strength measured at large strains. This behaviour should be interpreted with caution as triaxial extension data are often unreliable at axial strains $\varepsilon_{\mathrm{a}}>5-10 \%$ due to localization/necking of test specimen. Thus, the discrepancies between extension predictions and measured behaviour in extension test may either reflect limitations in the model or in the test data, but cannot be resolved successfully without obtaining reliable extension data at larger strains for higher OCRs. 

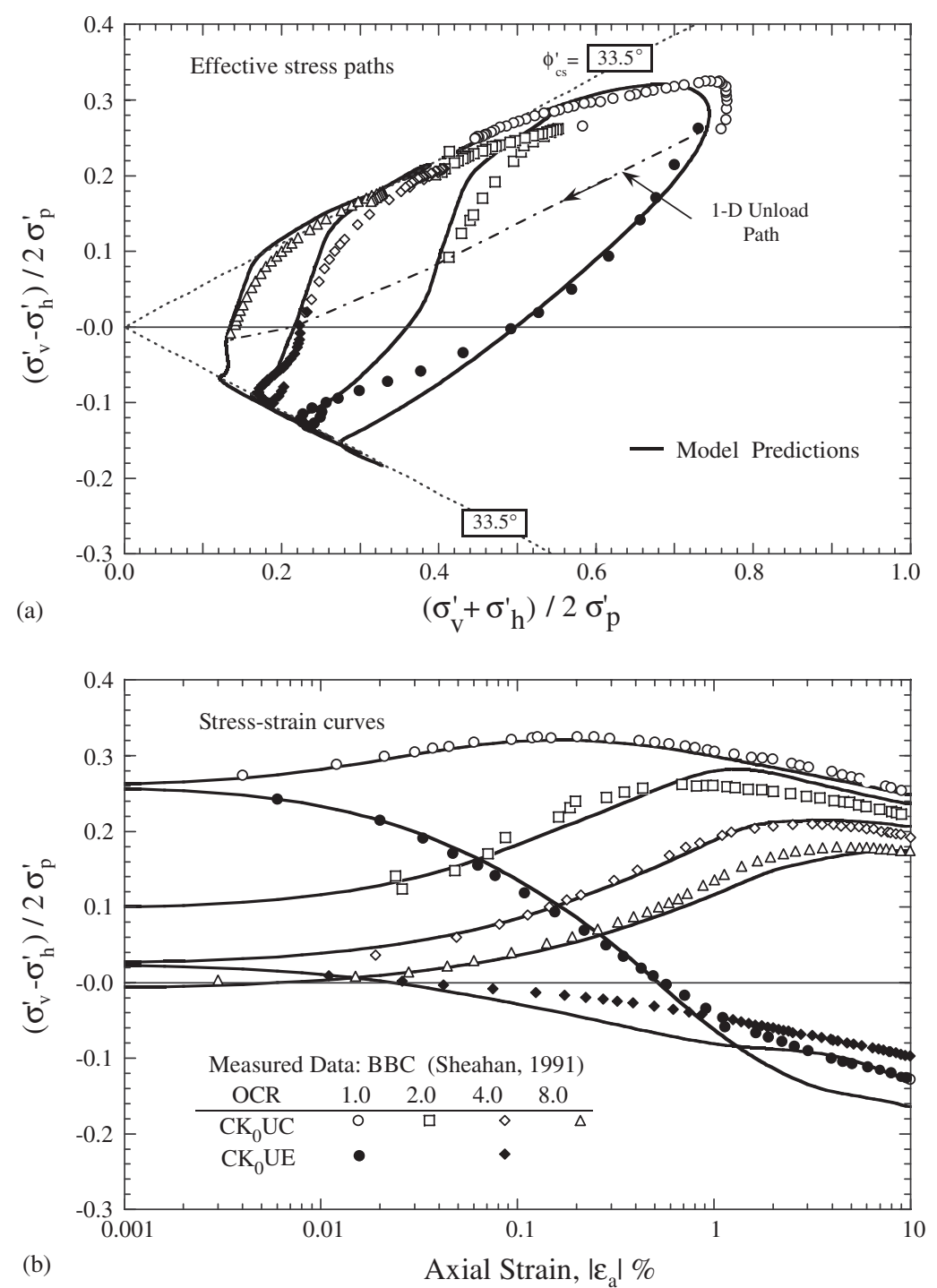

Figure 8. Effect of overconsolidation stress history on the undrained response of Boston Blue Clay.

Figures 7(b) and 8(b) show the stress-strain response of LCT and BBC in a log strain scale to highlight the importance of small strain nonlinearity. Many applications of advanced constitutive models for clays involving numerical tools such as the Finite Element Method, require accurate prediction of soil deformation at small strain levels $(<1 \%)$. Figure 9 compares the stress-strain curves for these two clays in the traditional space and show similar behaviour as a function of overconsolidation ratio. As can be seen from the figure, Boston Blue Clay is slightly stronger in compression for $\mathrm{OCR}<2$, whereas at larger $\mathrm{OCR}$ the strength is approximately the same for both soils. In extension, LCT is stronger for all OCR values. The axial strain at failure is smaller for LCT than for BBC at all values of OCR. 

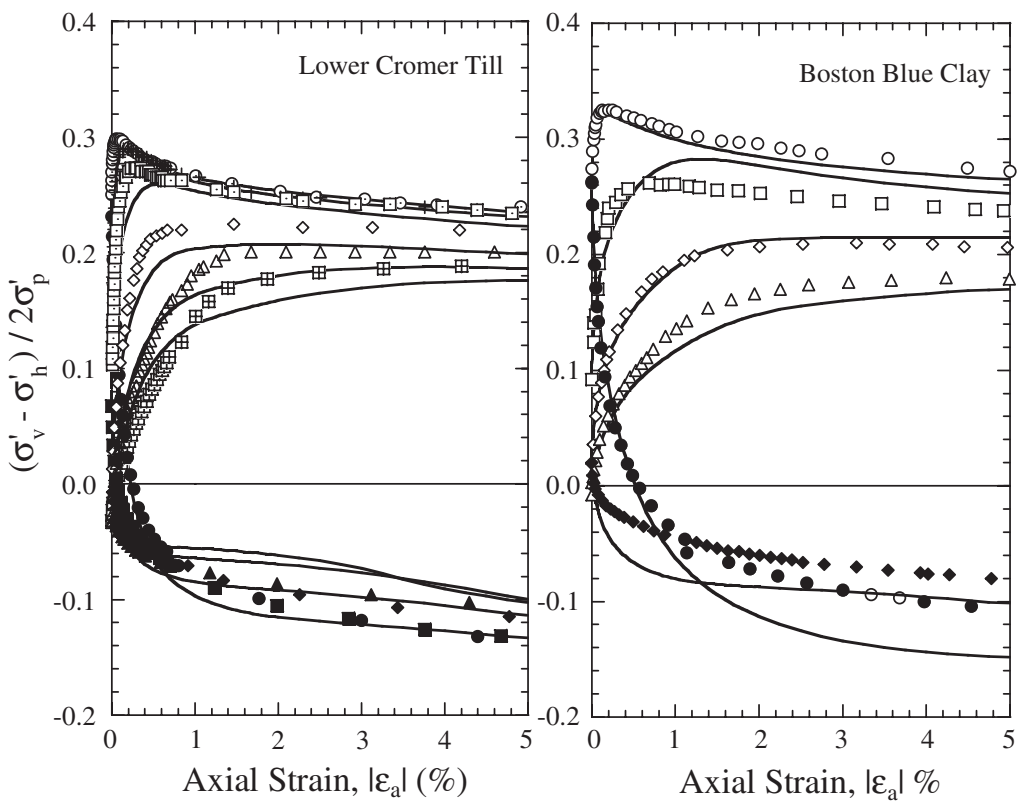

Figure 9. Stress-strain response of Lower Cromer Till and Boston Blue Clay during undrained triaxial shearing.

Figure 10 summarizes the predicted and measured conditions at peak shear strength as described by the undrained shear strength ratio $\left(s_{\mathrm{u}} / \sigma_{\mathrm{vc}}^{\prime}\right)$ and Skempton pore pressure parameter at failure, $A_{\mathrm{f}}\left[=\left(\Delta u-\Delta \sigma_{3}\right) /\left(\Delta \sigma_{1}-\Delta \sigma_{3}\right)\right]$ for these two soils. The predictions follow very closely a power law relation between the strength and overconsolidation ratios as proposed by Ladd and Foott [7] with exponent $m=0.7-0.8$ up to $\mathrm{OCR}=10$ and are in excellent agreement with measured data. For lightly overconsolidated specimens, $\mathrm{OCR}<1.5$, the model gives predictions of undrained strength that are higher than those predicted by the SHANSEP expression. For lightly overconsolidated specimens (i.e. OCR $<1.5-2$ ), an exponent of 0.90 and 0.80 for LCT and $\mathrm{BBC}$, respectively, describes the measured response better but significantly overpredicts the undrained strength for OCR $>2$ (cf. Figure 10). The predicted transition from contractive to dilative behaviour with increasing OCR is very well described by the model with the exception of $\mathrm{OCR}=1$. Parameter $A_{\mathrm{f}}$ decreases rapidly from an initial value of $0.95-1.05$ to $A_{\mathrm{f}} \sim 0.2$ for an OCR ranging from 1.5 to 1.7 , while the subsequent decrease is relatively small for higher OCRs. The discrepancy in $A_{\mathrm{f}}$ for $\mathrm{OCR}=1$ in compression may be attributed to slight 'apparent' preconsolidation induced by secondary compression of normally consolidated specimens as described by Gens [3].

\subsection{Non-triaxial modes of shearing}

Comparison of predictions with measured data for modes of shearing other than triaxial provides an assessment of predictive capabilities and limitation of the proposed model. Figures 11(a) and (b) show the effective stress paths and shear stress-strain response measured in undrained plane strain compression tests $\left(\mathrm{CK}_{0} \mathrm{UPSC}\right)$ for specimens with overconsolidation 

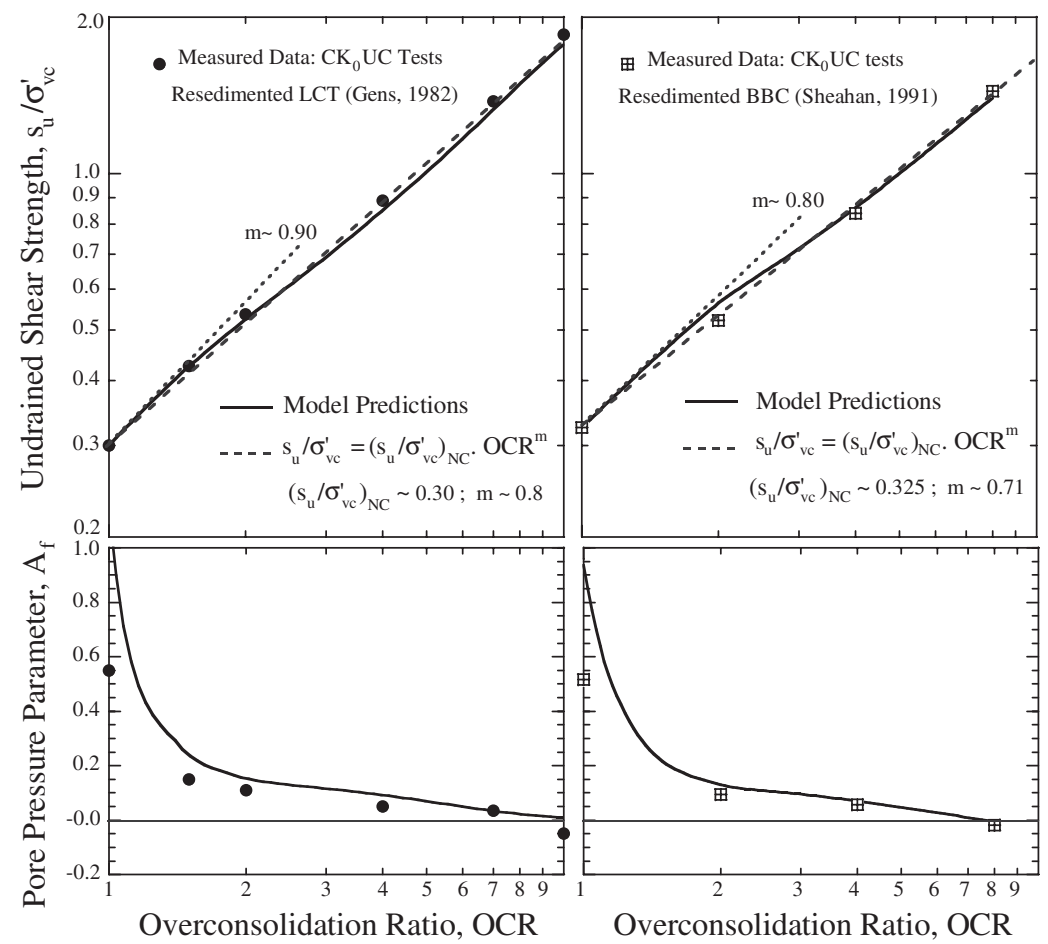

Figure 10. Evaluation of model predictions at peak shear stress conditions in triaxial conditions.

ratios, OCR $\leqslant 7$. All tests were performed at a shearing rate of $\Delta \dot{\varepsilon}_{\mathrm{a}}=0.04 \% / \mathrm{h}$. The model gives excellent predictions of measured stress-strain behaviour at small strains and undrained shear strength for all overconsolidated samples, but overestimates the undrained shear strength at $\mathrm{OCR}=1$. The MIT-S1 model is rate independent with input parameters that were calibrated with data obtained from tests at the standard shearing rate of $0.5 \% / \mathrm{h}$. While the differences in behaviour due to strain rate are small for overconsolidated specimens, they are significant for lightly overconsolidated clays (i.e. OCR $<1.5$ ). The predicted effective stress paths and stress obliquities are in good agreement with measured data, but the model does not describe the negative shear induced pore pressure measured in tests at small strains. Predicted peak friction angles are consistently at approximately $2-3^{\circ}$ higher than those measured (i.e. $33-35^{\circ}$ vs $30-32^{\circ}$ ).

Figure 12 compares MIT-S1 predictions with measured data for plane strain compression and extension tests on Boston Blue Clay at OCRs $=1,2$ and 4 as reported by Ladd and coworkers [14]. The results show the following:

1. For normally consolidated clay, the predicted peak shear strength in plane strain compression, $s_{\mathrm{uPSC}} / \sigma_{\mathrm{vc}}^{\prime}=0.34$, occurs at a small strain levels, $\varepsilon_{\mathrm{a}} \approx 0.2 \%$ and is in excellent agreement with the measured data. The model predicts post-peak strain softening in conjunction with positive shear induced pore pressures, which are in very good agreement with the measured data for $\varepsilon_{\mathrm{a}}<4-5 \%$. For strains larger than $5 \%$ the model converges to critical state conditions with no further softening, while observed behaviour shows increased softening. For plane strain extension, the predicted shear 

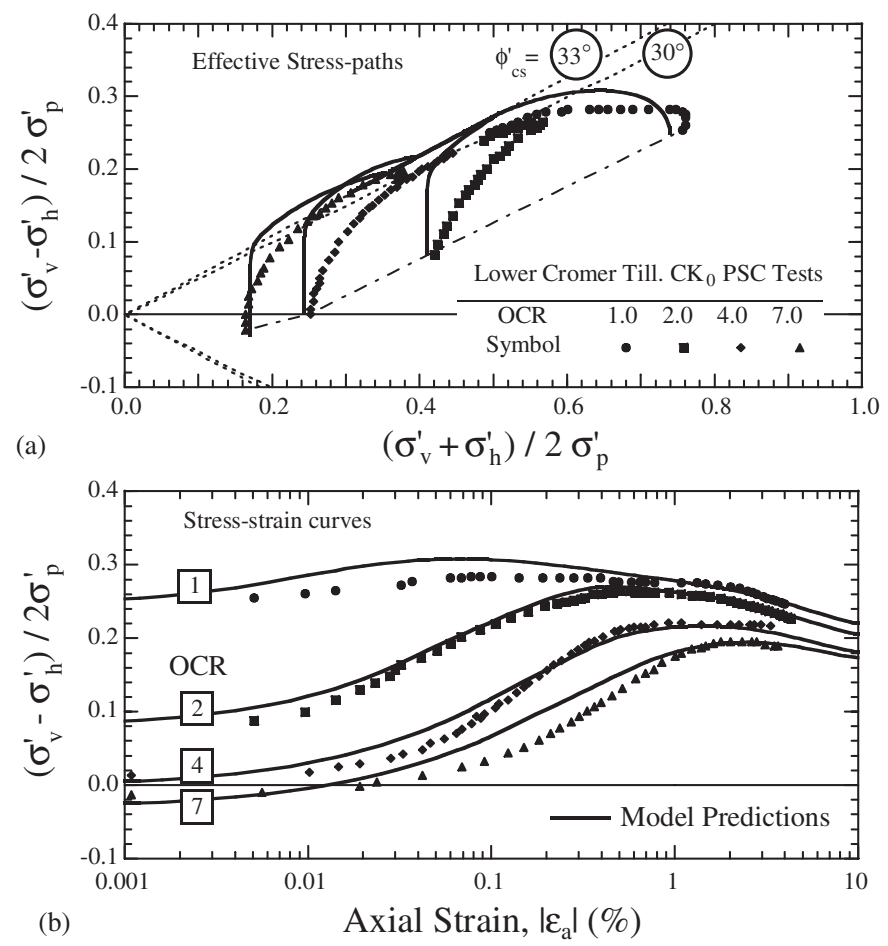

Figure 11. Comparison of predicted and measured undrained plane strain behaviour of Lower Cromer Till.

strength, $s_{\mathrm{uPSE}} / \sigma_{\mathrm{vc}}^{\prime}=0.24$, is mobilized at large strains $\left(\varepsilon_{\mathrm{a}} \approx 20 \%\right)$ and positive shear induced pore pressure is developed initially but then decreases as the sample tries to dilate (cf. Figure 12(a)). The measured extension data, on the other hand, shows significant scatter with undrained strength ranging from $s_{\mathrm{u}} / \sigma_{\mathrm{vc}}^{\prime}=0.19-0.26$ obtained at large strains, and mobilized friction angles well in excess of that predicted by the model and may be due to difficulties in actual pore pressure measurements. The extension data, in general, are not considered reliable for strains $\varepsilon_{\mathrm{a}}>5 \%$ [14].

2. For compression tests at $\mathrm{OCR}=2$, the undrained shear strength is mobilized at small strains $\varepsilon_{\mathrm{a}} \approx 1 \%$ and is characterized by a reversal from negative to positive shear induced pore pressures which is well predicted by the MIT-S1 model. In extension tests, the undrained shear strength is mobilized at large strains, with continuous positive shear induced pore pressure and mobilized friction angles, which exceed $50^{\circ}$. The model gives excellent prediction of the measured stress-strain behaviour for $\varepsilon_{\mathrm{a}} \leqslant 3 \%$, but predicts that the specimen dilates with the mobilized friction angle exceeding critical state conditions (i.e. $\phi^{\prime} \geqslant 37.9^{\circ}$ ). The undrained shear strengths and the stress-strain behaviour predicted by the model are in excellent agreement with measured data in both compression and extension modes.

3. At $\mathrm{OCR}=4$, the model predicts undrained shear strengths which are in excellent agreement with measured data in both compression and extension modes of shearing (within 5\%). Peak stress obliquity is well described (within $1-2^{\circ}$ ) in plane strain compression tests, while measurements in extension tests are not considered reliable. 

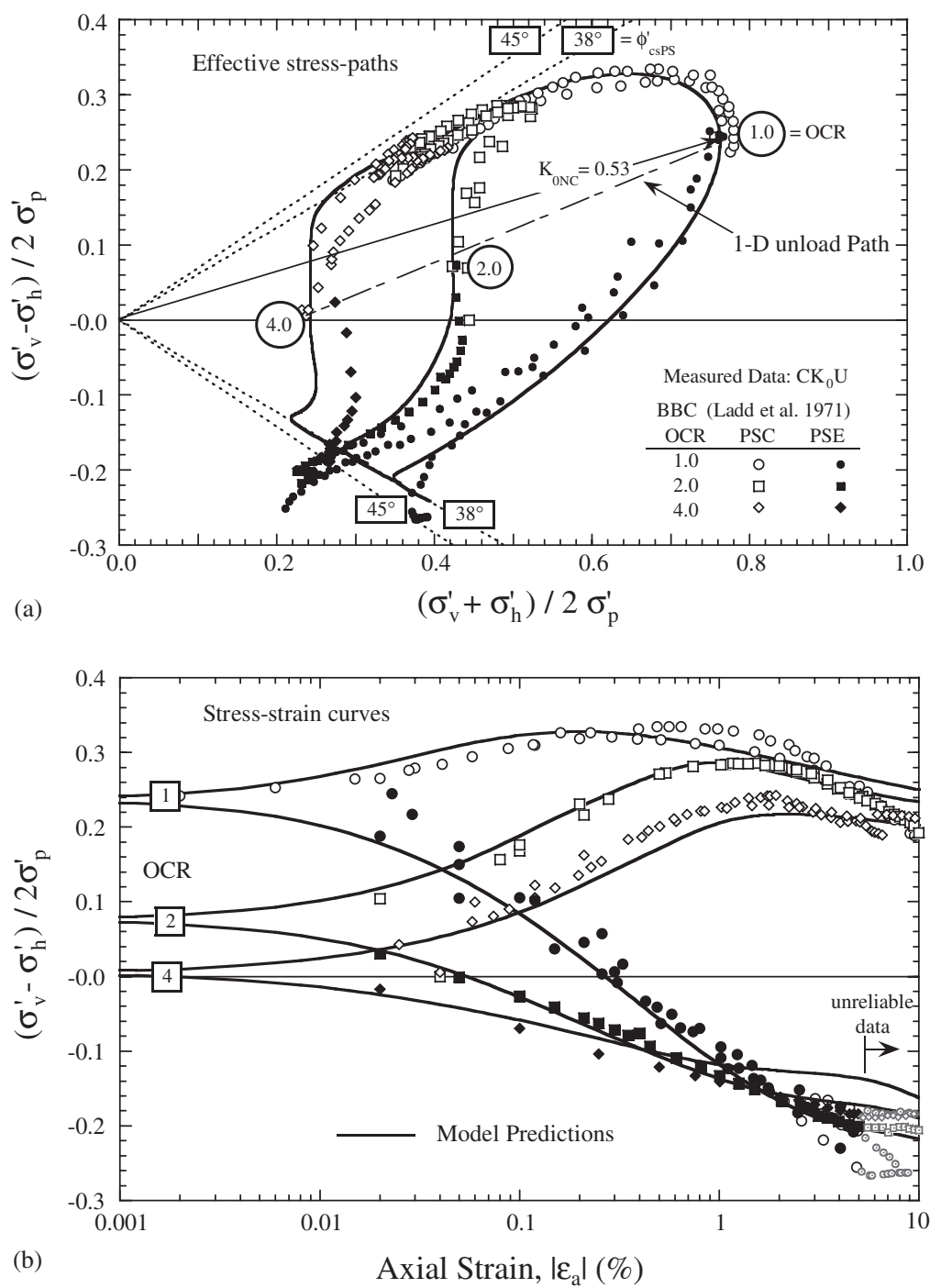

Figure 12. Comparison of predicted and measured undrained plane strain behaviour of Boston Blue Clay.

It should be noted that the MIT-S1 model predicts a unique critical state friction angle in all modes of plane strain shearing (i.e. $\phi_{\mathrm{PS}}^{\prime}=37.9^{\circ}$ ) due to the use of an isotropic failure criterion [15]. This is in contrast to previous developments at MIT (e.g. MIT-E3 model [13]) which assumed an anisotropic criterion for critical state failure conditions. However, MIT-S1 does describe differences in the peak friction angles for different shearing modes as a function of prior consolidation stress history (e.g. $\mathrm{CK}_{0}$ vs $\mathrm{CI}$ ). This development is in contrast to the anisotropic criterion used by previous models developed at MIT (e.g. MIT-E3 model) which only considered anisotropy resulting from $K_{0}$-consolidation stress history. For BBC, the MIT-S1 model predicts that $\phi_{\mathrm{PSA}}^{\prime}-\phi_{\mathrm{TC}}^{\prime} \approx 4.5^{\circ}$, while peak and large strain obliquities in extension mode follow $\phi_{\mathrm{PSP}}^{\prime}>\phi_{\mathrm{TE}}^{\prime}$. 
Another test routinely used in clay investigation is the direct simple shear, DSS, test. A large number of $\mathrm{CK}_{0} \mathrm{UDSS}$ tests have been conducted in resedimented BBC over the last 25 years at MIT [16] using the Geonor apparatus [17]. In this device, the sample is confined laterally by a wire-reinforced membrane to prevent lateral straining and undrained shearing is simulated by conducting constant volume (height) tests such that the total vertical stress is equal to the vertical effective stress. Experimental investigations report highly consistent measurements of engineering properties but there is still controversy in the actual interpretation of test results. This is due, in large part, to the fact that boundary conditions are not well controlled and that in standard tests without measurement of the lateral traction, $\sigma_{\mathrm{h}}^{\prime}$, the complete state of stresses is not known.

The measured data are considered reliable for shear strains in the range $0.1 \leqslant \gamma \leqslant 10 \%$, reflecting measurement limitations at small strains and the unloading that occurs at large strains. Figures 13(a) and 13(b) compare model predictions and measured effective stress paths (acting on horizontal planes in the sample, i.e. $\sigma_{\mathrm{v}}^{\prime}$ vs $\tau$ ) and the shear stress-strain behaviour for $\mathrm{CK}_{0}$ UDSS tests on recent resedimented $\mathrm{BBC}$ for nominal OCRs $=1,2,4$ and 8 . The figures
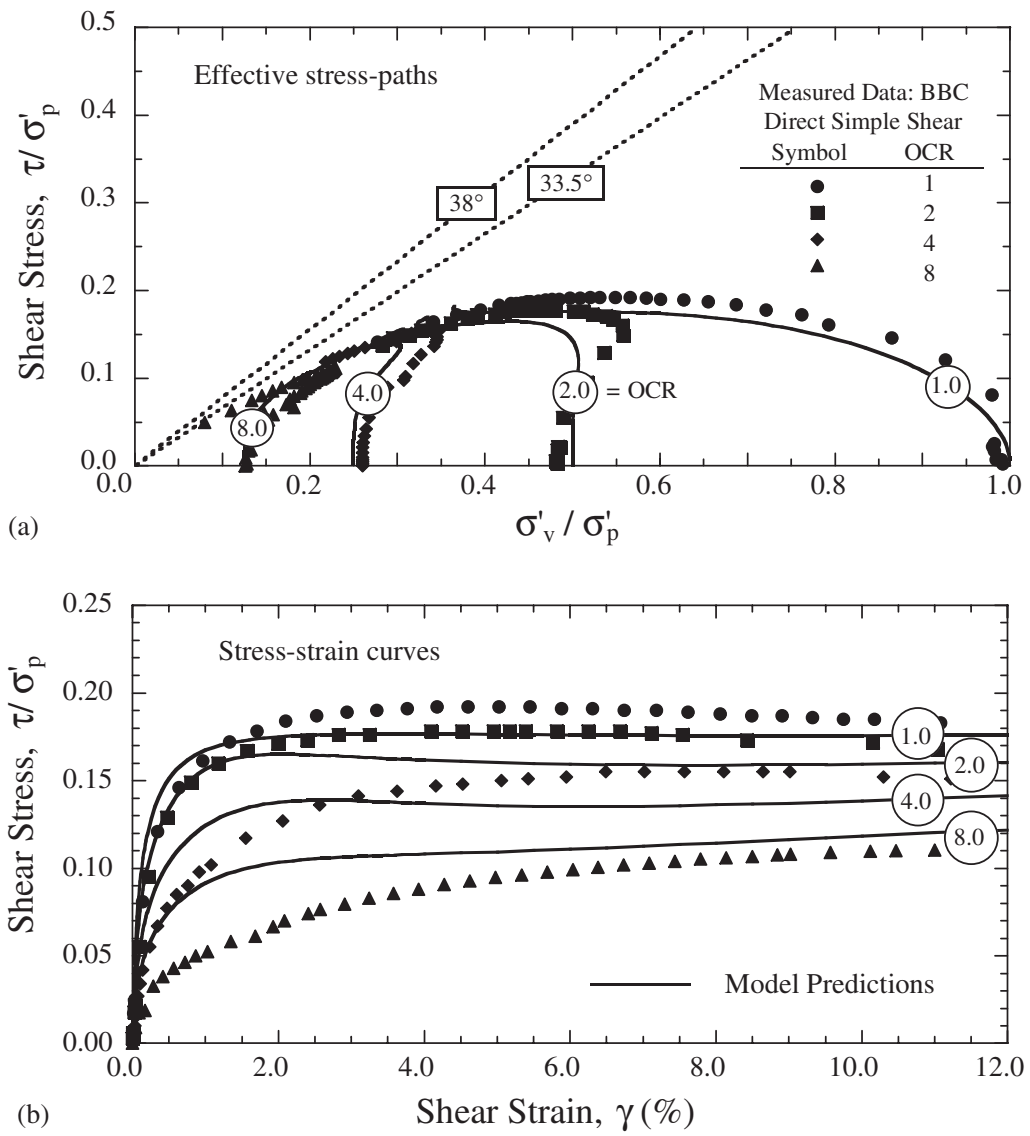

Figure 13. Comparison of predicted and measured undrained simple shear behaviour of Boston Blue Clay. 
present model predictions for $K_{0 \mathrm{NC}}=0.49$ which are consistent with recent measurements in the triaxial apparatus, however the actual $K_{0}$ value is not known as $\sigma_{\mathrm{h}}^{\prime}$, is not measured using standard test equipment during either $K_{0}$-consolidation or undrained shearing. The undrained strength in this device, $s_{\mathrm{uDSs}}$, is taken to be the measured maximum horizontal shear stress, $\tau_{\text {hmax }}$.

At $\mathrm{OCR}=1$, model predictions are in good agreement with the measured stress-strain behaviour (cf. Figure 13(b)) and effective stress paths (cf. Figure 13(a)) while under-predicting the undrained shear strength by $5-10 \%$ (predicted $s_{\mathrm{uDSS}} / \sigma_{\mathrm{vc}}^{\prime}=0.18$ vs measured $\left.s_{\mathrm{uDSS}} / \sigma_{\mathrm{vc}}^{\prime}=0.19-0.20\right)$. This difference can be explained, in part, by slightly different initial $K_{0}$ conditions as discussed by Pestana [1]. At OCR $=2$ and 4 , the model gives excellent predictions of undrained shear strength and maximum stress obliquities (i.e. $\tau / \sigma_{\mathrm{v}}^{\prime}$ ) mobilized in horizontal planes, but significantly overpredicts the stiffness for $\gamma<2 \%$ for OCR $=4$. Measured effective stress paths show initial negative induced pore pressure up to the peak shear stress, after which softening occurs, which is well predicted by the model. However, the model characteristic feature is the second reversal of shear induced pore pressure occurring at $\gamma=$ $8-10 \%$ (limits of reliable stress-strain data) but is not observed in measured data. Critical state conditions are achieved at large strains, $\gamma \approx 20 \%$ while measured data shows increasing strain softening resulting from the unloading that occurs at large strains [18]. For OCR of 8 the model gives good predictions of undrained shear strength at large strains $(\gamma=10 \%)$, but overestimates significantly the shear stiffness throughout the test. In all cases, the undrained strength is achieved at large strains $\gamma \approx 20 \%$. The maximum stress obliquity, $\psi_{\max }\left(=\left[\tau_{\mathrm{h}} / \sigma_{\mathrm{v}}^{\prime}\right]_{\max }\right)$ predicted at large strains increases with increasing OCR and is in excellent agreement with measured data for all OCRs.

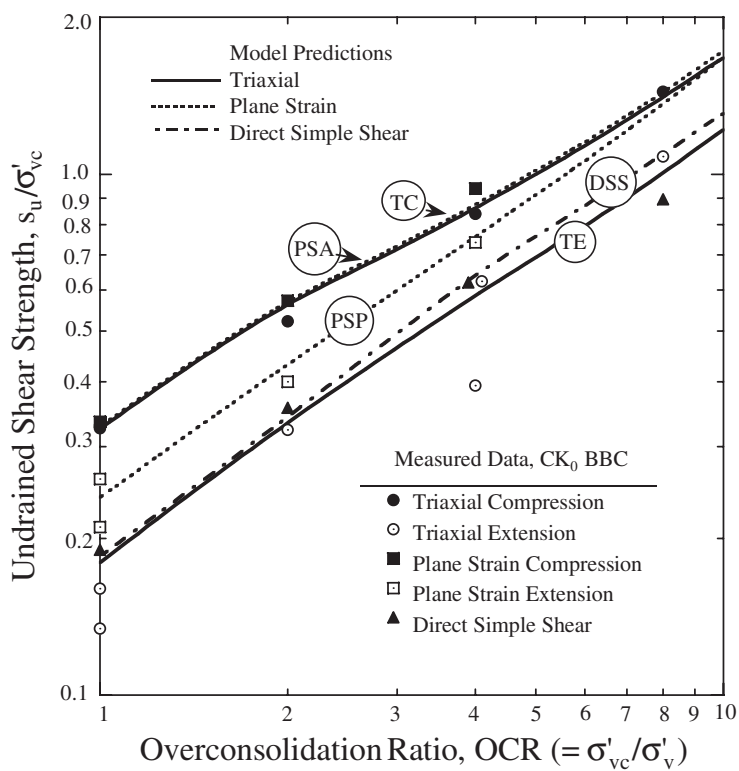

Figure 14. Evaluation of model predictions of undrained strength of $\mathrm{CK}_{0}$ consolidated Boston Blue Clay for various modes of shearing. 
Figure 14 summarizes MIT-S1 model predictions of undrained shear strength $\left(s_{\mathrm{u}} / \sigma_{\mathrm{vc}}^{\prime}\right)$ for triaxial, plane strain and DSS modes of shearing with overconsolidation ratios up to 8, compared with measured data for resedimented Boston Blue Clay. The model predicts the highest strengths in plane strain active tests and the lowest in DSS tests. The undrained strength in triaxial extension is slightly higher than those from DSS for all OCRs considered. Model predictions are in excellent agreement with measured data in compression (triaxial and plane strain) and DSS tests with OCRs $\leqslant 8$. For extension tests the model gives very good agreement with measured data, considering the scatter in some tests and the difficulties involved in extension tests at large strains. The predictions follow very closely a power law relation between the strength and OCR with exponents ranging from $m=0.70$ in compression modes to $m=0.75$ in extension modes. These results are in excellent agreement with SHANSEP parameters
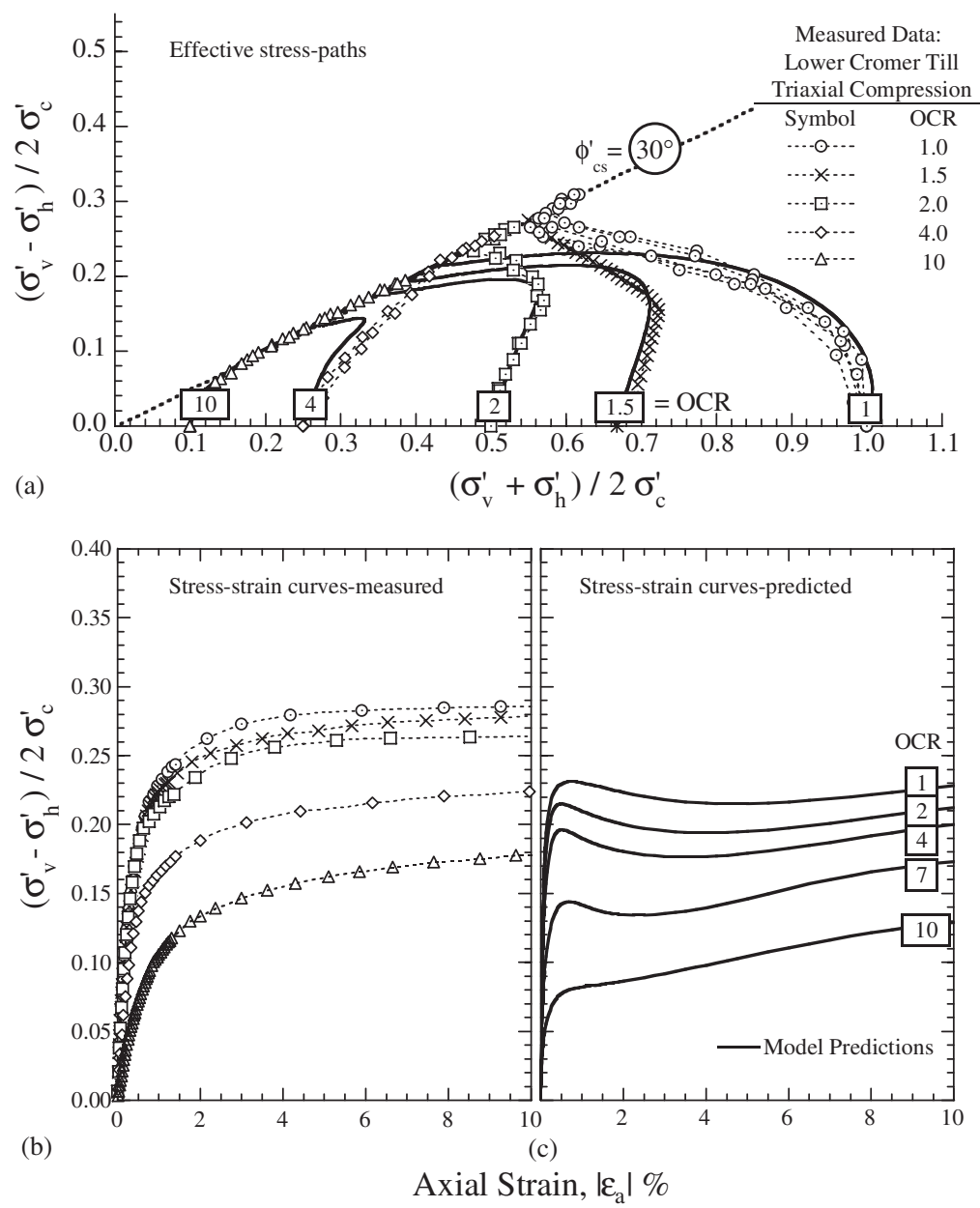

Figure 15. Effect of consolidation stress history on the undrained behaviour of isotropically consolidated Lower Cromer Till. 
proposed by Ladd and Foott [7] for OCR $<8$. Undrained strength anisotropy is most pronounced in soft normally and lightly overconsolidated clays (OCR $\leqslant 2.0$ ).

\subsection{Effect of stress history on isotropically consolidated specimens}

Figures 15(a)-15(c) show comparison between measured and predicted effective stress paths and stress-strain behaviour of isotropically consolidated samples of LCT with OCR $\leqslant 10$. Model predictions are in qualitatively good agreement with measured data, but the model underpredicts the secant shear stiffness for axial strains larger than approximately $1 \%$ for both triaxial compression and extension modes. This result suggests that there are large differences in the small strain stiffness of $K_{0}$ and hydrostatically consolidated specimens. The MIT-S1 model assumes that the small strain stiffness is only dependent on the current density and confining stress level and hence cannot describe the large differences in the shear stiffness of $\mathrm{CK}_{0} \mathrm{U}$ and CIU tests on LCT. This issue deserves further study especially in the light of recent measurements of small strain anisotropy reported by Jamiolkowski and coworkers [12]. Figure 16 shows the normalized undrained strength, $s_{\mathrm{u}} / \sigma_{\mathrm{vc}}^{\prime}$ (where $\sigma_{\mathrm{vc}}^{\prime}$ is the vertical consolidation stress) as a function of OCR. The model predicts similar trends for triaxial compression and extension but consistently underpredicts the undrained shear strength by 10 $20 \%$ for all OCRs. Figure 16 also shows the relative change of the undrained strength as a function of OCR when normalized by the observed value for normally consolidated samples. The model gives similar predictions as the SHANSEP expression (i.e. $s_{\mathrm{u}} / \sigma_{\mathrm{vc}}^{\prime}=\left(s_{\mathrm{u}} / \sigma_{\mathrm{vc}}^{\prime}\right)_{\mathrm{NC}}$ $\mathrm{OCR}^{\mathrm{m}}$ ) with an exponent of approximately 0.8 .

Figure 17 compares predictions of effective stress paths for undrained triaxial compression tests with measured data for isotropically consolidated samples of Boston Blue Clay with initial $\mathrm{OCR}=1,2,4,8$. The model gives excellent predictions of maximum stress obliquities for all OCRs and of shear induced pore pressures for OCR $=1,4$ and 8 . The experiment at OCR had some technical difficulties and the stress-strain response is not considered reliable. The model gives excellent predictions of the stress-strain curves at all OCR up to $2 \%$, while slightly

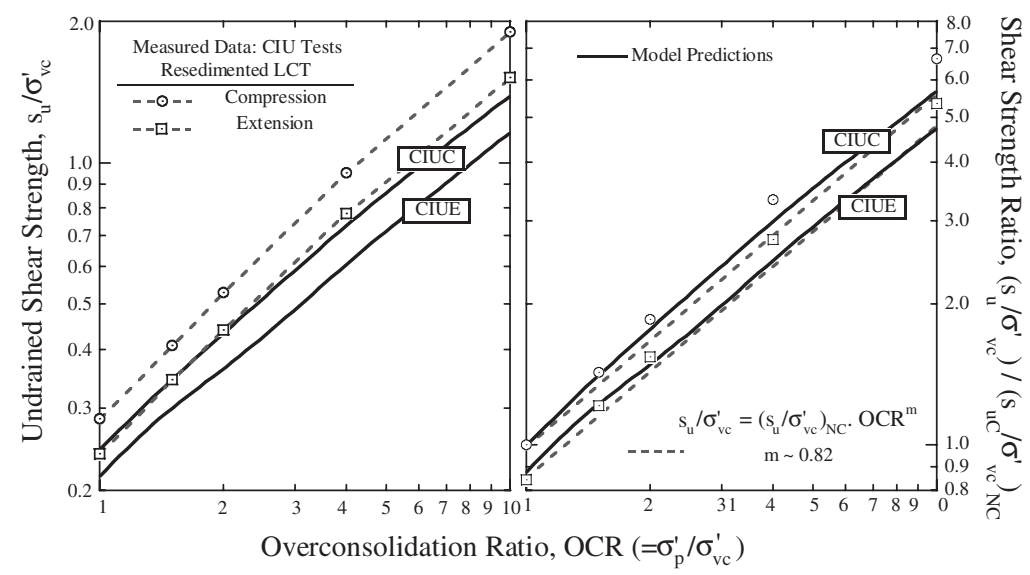

Figure 16. Summary of undrained strength as a function of consolidation stress history for isotropically consolidated Lower Cromer Till. 


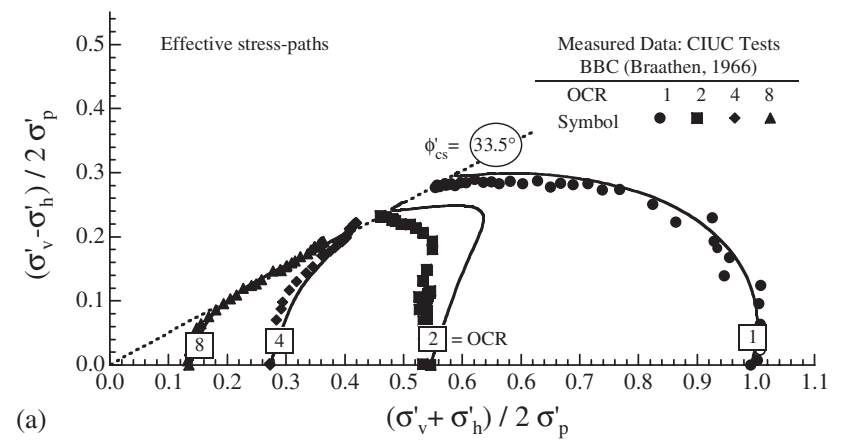

(a)

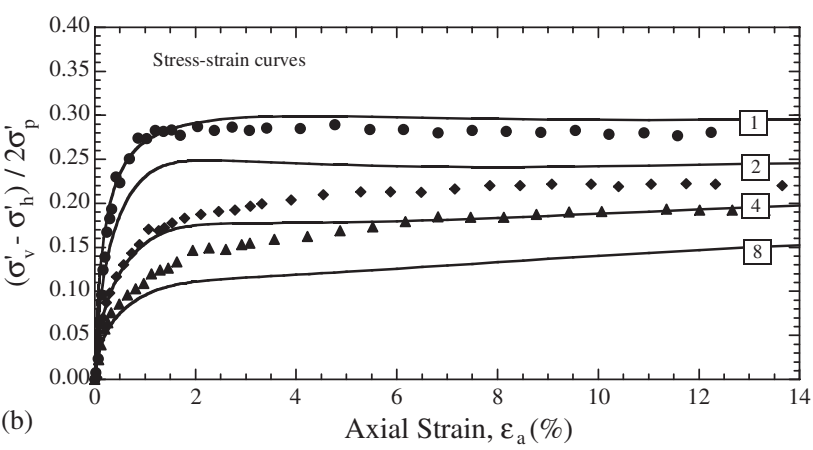

Figure 17. Effect of consolidation stress history on the undrained behaviour of isotropically consolidated Boston Blue Clay.

underestimating the stiffness at higher strains. Model predictions of undrained shear strength, as described by the undrained strength ratio $\left(s_{\mathrm{u}} / \sigma_{\mathrm{vc}}^{\prime}\right)$, follow very closely a power law relation between the strength and OCR with exponent $m=0.725 \pm 0.025$ and are in excellent agreement with measured data for OCR $<2$ while slightly underestimating $s_{\mathrm{u}}$ (by 10-20\%) for OCR $=8$. The predicted Skempton pore pressure parameter at failure, $A_{\mathrm{f}}\left[=\left(\Delta u-\Delta \sigma_{3}\right) /\left(\Delta \sigma_{1}-\Delta \sigma_{3}\right)\right]_{\mathrm{f}} t$ with OCR is in excellent agreement with measured data at all OCRs as seen in Figure 18.

\section{DRAINED BEHAVIOUR}

This section focuses on MIT-S1 predictions of standard drained triaxial compression tests for isotropically and $K_{0}$ consolidation stress histories. Drained tests on clays are far less common and a consistent database is not readily available for many clays. For BBC, some excellent quality drained tests have been performed at MIT primarily for consulting projects. Perhaps the most extensive and comprehensive database is that of resedimented Lower Cromer Till and reported by Gens [3]. The test database include drained shear tests on $K_{0}$ and isotropically consolidated specimens with overconsolidation ratios, $\mathrm{OCR} \leqslant 10$, as well as numerous special stress path tests used to evaluate particular aspects of the critical state framework of soil behaviour [19]. Figure 19 compares MIT-S1 predictions with measured data from a series of drained triaxial compression tests $\left(\mathrm{CK}_{0} \mathrm{DC}, 1.0 \leqslant \mathrm{OCR} \leqslant 7.0\right)$ sheared at a strain 


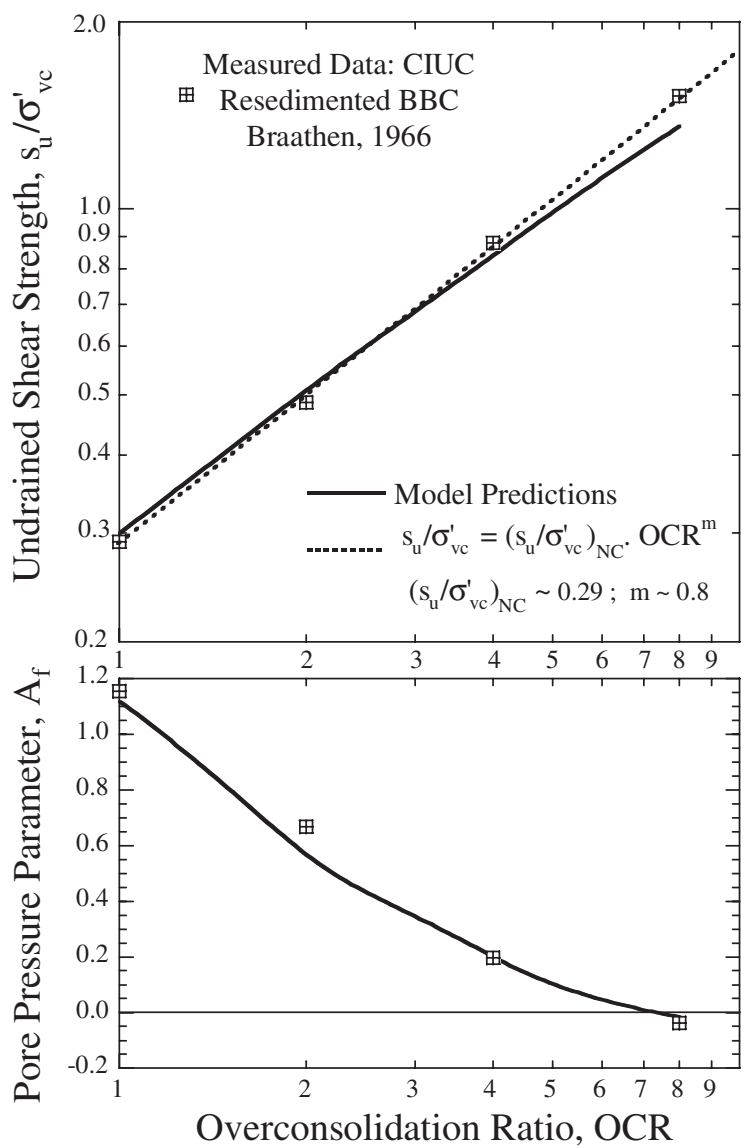

Figure 18. Summary of peak conditions for compression tests on isotropically consolidated BBC: undrained shear strength, $s_{\mathrm{u}} / \sigma_{\mathrm{vc}}^{\prime}$ and Skempton's pore pressure parameter, $A_{\mathrm{f}}$.

rate $\dot{\varepsilon}_{\mathrm{a}} \approx 0.02 \% / \mathrm{h}$. Although the model gives excellent predictions of the measured volumetric strains at all OCRs (and hence matches the measured critical state conditions), it slightly overpredicts the secant shear stiffness at strains $1 \% \leqslant \varepsilon_{\mathrm{a}} \leqslant 5 \%$. The model correctly captures the transition from contractive to dilative as the overconsolidation ratio increases. At OCR $\sim 7$, the material shows minimal contractive response (see Figure 19).

Figure 20 compares MIT-S1 model predictions with measured data from a series of standard drained triaxial compression tests on isotropically consolidated specimens (i.e. CIDC) with $\mathrm{OCR}=1,1.25,1.5,2,4,10$. The shear stress is normalized by the maximum mean effective stress, $\sigma_{\mathrm{p}}^{\prime}$. As the overconsolidation ratio increases, the behaviour changes from contractive to nearly neutral (i.e. no volume change at OCR $\sim 5$ ) to dilative at higher OCRs $(\mathrm{OCR}=10)$. In general, the shear stress-strain response and volumetric behaviour are very well described by MIT-S1 although the model slightly underpredicts the measured dilation at high OCR's (OCR $=10)$. Overall, the volumetric behaviour predicted by the model is in excellent agreement with measured data. 


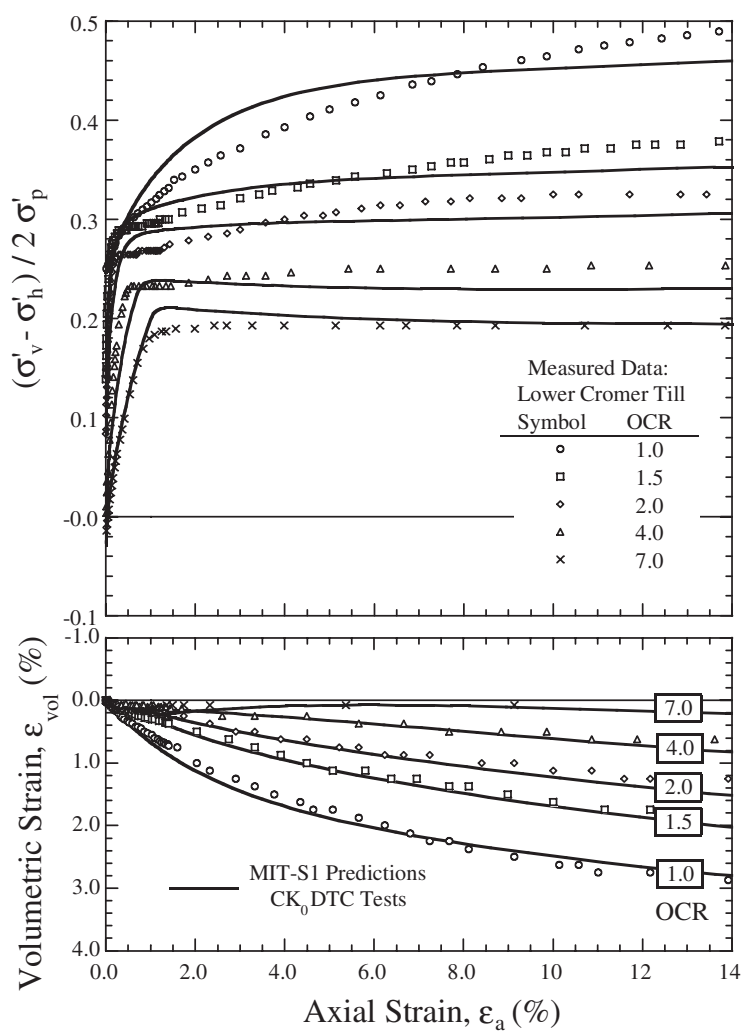

Figure 19. Effect of overconsolidation on the drained response of $K_{0}$-consolidated Lower Cromer Till.

\section{CONCLUSIONS}

This paper gives a detailed evaluation of the predictive capabilities and limitations of a new constitutive model, MIT-S1 to describe the rate independent behaviour of clays. Input parameters for the model are obtained from standard types of laboratory tests using a consistent procedure, which is illustrated for Lower Cromer Till. Model evaluation is investigated through comparison with results from an extensive program of laboratory element tests on Lower Cromer Till and Boston Blue Clay. Extensive comparison of model predictions with measured undrained triaxial, plane strain and direct simple shear stress on $K_{0}$-consolidated specimens show that MIT-S1 describes accurately the stress-strain-strength properties for OCR $<10$. Overall, comparisons with measured data from undrained shear tests performed in different modes of shearing and for high overconsolidation ratios show that the model: (a) gives excellent predictions of maximum shear stress conditions and gives a good description of the observed non-linear shear stress-strain behaviour. The model also describes the anisotropic shear stressstrain-strength conditions resulting from different consolidation stress histories. The MIT-S1 model remedies two previously reported limitations: (1) the stress obliquity is well described, especially at high OCR; and (2) the model simulates the measured tendency of the soil to dilate (negative shear induced pore pressures) when sheared to large strains in extension tests. 


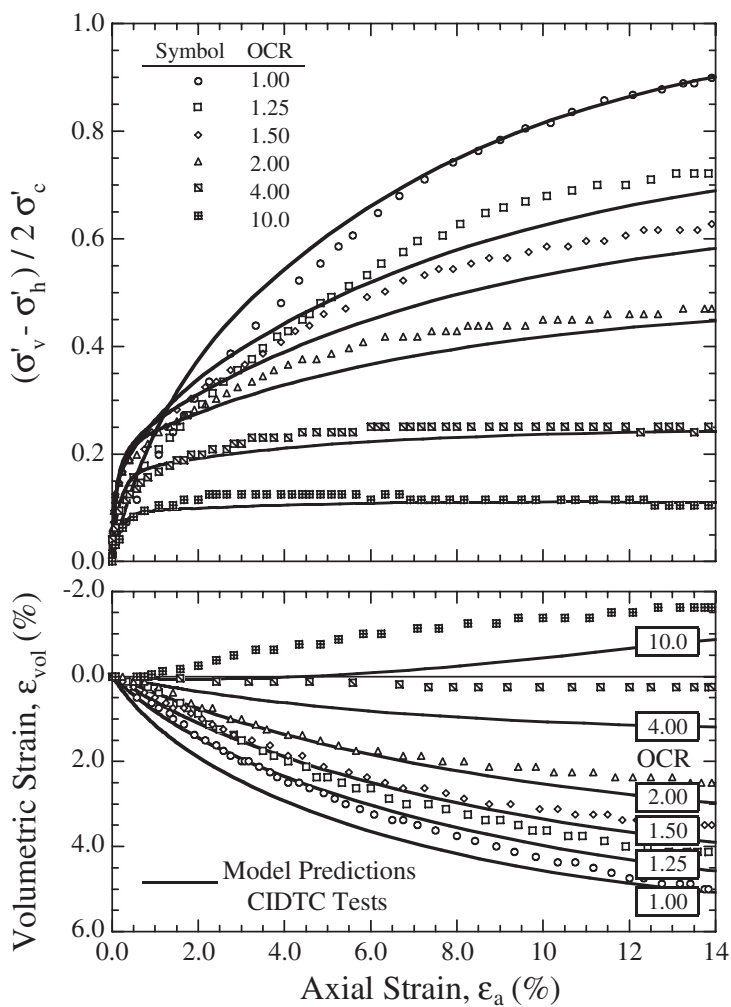

Figure 20. Effect of overconsolidation on the drained response of isotropically consolidated Lower Cromer Till.

The test database for LCT also includes drained shear tests on $K_{0}$ and isotropically consolidated specimens. Overall, the model gives excellent prediction of the transition from contractive to dilative volumetric response with increasing overconsolidation ratio, OCR. The model also gives qualitatively good predictions of the stress-strain response at all OCR for $K_{0}$ and isotropically consolidated samples. In general, the model slightly underestimates the stiffness for isotropically consolidated samples at all OCR. Finally, model predictions are in excellent agreement with measured volumetric response at all OCRs.

\section{ACKNOWLEDGEMENTS}

The authors would like to acknowledge INTEVEP, S.A. and the Gilbert W. Winslow Career Development Chair at MIT for supporting this research. Additional support was provided by the National Science Foundation, CAREER award CMS-9623979.

\section{REFERENCES}

1. Pestana JM. A unified constitutive model for clays and sands. Sc.D. Thesis, Department of Civil \& Environmental Engineering, Massachusetts Institute of Technology, Cambridge, MA, 1994. 
2. Pestana JM, Whittle AJ. Formulation of a unified constitutive model for clays and sands. International Journal for Numerical and Analytical Methods in Geomechanics 1999; 23:1215-1243.

3. Gens A. Stress-strain and strength of a low plasticity clay. Ph.D. Thesis at Imperial College, London University, 1982; 856pp.

4. Sheahan TC. An experimental study of the time-dependent undrained shear behaviour of resedimented clay using automated stress path triaxial equipment. Sc.D. Thesis, MIT, Cambridge, MA, 1991; 952pp.

5. Sheahan TC, Germaine JT, Ladd CC. Automated triaxial testing of soft clays: an upgraded commercial system. ASTM, Geotechnical Testing Journal 1990; 13(3):153-163.

6. Dyvik R, Lacasse S, Martin RT. Coefficient of lateral stress from oedometer cell. Proceedings of the 11th International Conference on Soil Mechanics and Foundation Engineering, San Francisco, 1985; 2:1003-1006.

7. Ladd CC, Foott R. New Design Procedure for Stability of Soft Clays. ASCE, Journal of the Geotechnical Engineering Division 1974; 100(GT7):763-786.

8. Pestana JM, Whittle AJ. Compression model for cohesionless soils. Géotechnique 1995; 45(4):611-631.

9. Hight D. Personal Communication, 1993.

10. Mayne PW, Kulhawy FH. $K_{0}$-OCR relationships in soils. ASCE, Journal of the Geotechnical Engineering Division 1982; 108(GT6):851-872.

11. Jardine RJ, Symes MJPR, Burland JB. The measurement of soil stiffness in the triaxial apparatus. Géotechnique 1984; 34(3):323-340.

12. Jamiolkowski M, Lancellota R, LoPresti DCF. Remarks on the stiffness at small strains of six Italian clays. Sapporo Conference 1994; I:95-114.

13. Whittle AJ, Kavvadas M. Formulation of the MIT-E3 constitutive model for overconsolidated clays. ASCE, Journal of Geotechnical Engineering 1994; 120(1):173-198.

14. Ladd CC, Bovee R, Edgers L, Rixner JJ. Consolidated-undrained plane strain tests on Boston Blue Clay. Research Report R71-13. Department of Civil Engineering, MIT, Cambridge, MA, 1971.

15. Matsuoka H, Nakai T. Stress-deformation and strength characteristics under three different principal stresses. Proceedings of the Japanese Society of Civil Engineers 1974; 232:59-70.

16. Ladd CC, Edgers L. Consolidated-undrained direct simple shear tests on Boston Blue Clay. Research Report R72-82. Department of Civil Engineering, MIT, Cambridge, MA, 1972.

17. Bjerrum L, Landva A. Direct simple shear tests on Norwegian quick clays. Géotechnique 1966; 16(1):1-20.

18. DeGroot DJ, Germaine JT, Ladd CC. Influence of non-uniform stresses imposed by the direct simple shear apparatus on measured stress-strain behaviour. ASCE, Journal of Geotechnical Engineering 1994; 120(5):892-912.

19. Roscoe KH, Burland JB. On the generalised stress-strain behaviour of 'wet' clay. In Engineering Plasticity, Heyman J, Leckie FA (eds). Cambridge University Press: Cambridge, 1968; 535-609. 